\title{
Impact of Galectin-Receptor Interactions on Liver Pathology During the Erythrocytic Stage of Plasmodium berghei Malaria
}

\author{
Yifan Wu ${ }^{1}$, Shiguang Huang ${ }^{2 *}$, Siyu Xiao ${ }^{1}$, Jian $\mathrm{He}^{1,3}$ and Fangli $\mathrm{Lu}^{1,4,5 *}$ \\ 1 Department of Parasitology, Zhongshan School of Medicine, Sun Yat-sen University, Guangzhou, China, ${ }^{2}$ School of \\ Stomatology, Jinan University, Guangzhou, China, ${ }^{3}$ Public Experimental Teaching Center, Sun Yat-sen University, \\ Guangzhou, China, ${ }^{4}$ Department of Clinical Laboratory, The Seventh Affiliated Hospital, Sun Yat-sen University, Shenzhen, \\ China, ${ }^{5}$ Key Laboratory of Tropical Disease Control of Ministry of Education, Sun Yat-sen University, Guangzhou, China
}

OPEN ACCESS

Edited by:

Albert Descoteaux,

Université du Québec, Canada

Reviewed by:

Ines Coelho,

New University of Lisbon, Portugal

Tarun Keswani,

Massachusetts General Hospital and Harvard Medical School, United States

*Correspondence:

Fangli Lu

fanglilu@yahoo.com Shiguang Huang thshg@126.com

Specialty section: This article was submitted to Microbial Immunology, a section of the journal

Frontiers in Immunology

Received: 13 August 2021 Accepted: 05 October 2021 Published: 24 November 2021

Citation:

Wu Y, Huang S, Xiao S, He J and Lu F (2021) Impact of Galectin-Receptor Interactions on Liver Pathology During the Erythrocytic Stage of Plasmodium berghei Malaria.

Front. Immunol. 12:758052. doi: 10.3389/fimmu.2021.758052
Hepatopathy is frequently observed in patients with severe malaria but its pathogenesis remains unclear. Galectins are evolutionarily conserved glycan-binding proteins with pleiotropic roles in innate and adaptive immune responses, and exhibit pivotal roles during Plasmodium spp. infection. Here, we analyzed the impact of blockage of galectinreceptor interactions by treatment with alpha $(\alpha)$-lactose on liver immunopathology during the erythrocytic stage of malaria in mice infected with Plasmodium berghei ANKA (PbANKA). Our results found that compared with PbANKA-infected mice (malarial mice), blockage of galectin-receptor interactions led to decreased host survival rate and increased peripheral blood parasitemia; exacerbated liver pathology, increased numbers of $\mathrm{CD}^{+} 8^{+}$macrophages and apoptotic cells, and increased parasite burden in the livers on days 5 and 7 post infection (p.i.) as well as increased mRNA expression levels of galectin-9 (Gal-9) and its receptor, the T cell immunoglobulin domain and mucin domain protein 3 (Tim-3), interferon (IFN) $\alpha$, IFN $\gamma$, and the triggering receptor expressed on myeloid cells (TREM)- 1 in the livers or spleens of PbANKA-infected mice on day 7 p.i. Observed by transmission electron microscopy, the peritoneal macrophages isolated from malarial mice with $\alpha$-lactose treatment had more pseudopodia than those from malarial mice. Measured by using quantitative real-time reverse transcription-polymerase chain reaction assay, the mRNA expression levels of Gal-9, IFN $\alpha$, IFN $\beta$, IFN $\gamma$, and TREM-1 were increased in the peritoneal macrophages isolated from malarial mice with $\alpha$-lactose treatment in comparison of those from malarial mice. Furthermore, significant positive correlations existed between the mRNA levels of Gal- 9 and Tim-3/IFN $\gamma / T R E M-1$ in both the livers and the peritoneal macrophages, and between Gal-9 and Tim-3/TREM-1 in the spleens of malarial mice; significant positive correlations existed between the mRNA levels of Gal-9 and IFN $\gamma$ in the livers and between Gal-9 and IFN $\alpha$ in the peritoneal macrophages from malarial mice treated with $\alpha$-lactose. Our data suggest a potential role of galectin- 
receptor interactions in limiting liver inflammatory response and parasite proliferation by down-regulating the expressions of IFN $\alpha$, IFN $\gamma$, and TREM-1 during PbANKA infection.

Keywords: Plasmodium berghei, liver, macrophage, Gal-9, Tim-3, IFN $\alpha$, IFN $\gamma$, TREM-1

\section{INTRODUCTION}

Plasmodium falciparum can cause severe disease manifested by cerebral malaria, difficulty breathing, difficulty urinating, hypoglycemia, lactic acidosis, severe anemia, jaundice, and liver involvement (1). In malaria patients with jaundice, histopathological changes of damaged hepatocytes, congestion of liver cells, hemozoin deposition, inflammatory infiltrates, and cholestasis as well as hyperplastic Kupffer cells have been demonstrated (2-4). Kupffer cell activation is an effective mechanism for regulating the host response to malaria liver-stage infection (5). In the erythrocytic stage of $P$. falciparum malaria, parasitized red blood cells (pRBCs) are sequestered within human small blood vessels. The degraded hemozoin (malarial pigment) is phagocytized by local tissue macrophages such as Kupffer cells and alveolar macrophages (6, 7). During Plasmodium liver-stage infection, Kupffer cells from Plasmodium-infected livers produce high levels of hepatocyte growth factor, which plays multiple roles during primary malaria hepatocyte infection and triggers apoptosis of infected hepatocytes (5). So far, several members of the triggering receptor expressed on myeloid cells (TREM) family including TREM-1, TREM-2, TREM3, and TREM-4 have been identified, in which activation of TREM1 amplifies inflammation, whereas TREM-2 signaling reduces inflammation (8-10). It has been reported that TREM-1 is a master regulator of Kupffer cell activation, which escalates chronic liver inflammatory responses, activates hepatic stellate cells, and promotes liver fibrosis (11). A study has demonstrated that Trem-2deficient mice infected with $P$. berghei ANKA (PbANKA) sporozoites are more susceptible to liver-stage infection than their wild-type counterparts, and TREM-2 is involved in host responses against the malaria parasite (12).

Galectins are evolutionarily conserved glycan-binding proteins with diverse roles in innate and adaptive immune responses (13). Evidence showed that galectins are also involved in host-microbial recognition and pathogen subversion of immune responses (14). Galectin-9 (Gal-9) plays a critical role in regulating the fate of effector $\mathrm{T}$ cells, and can induce apoptosis of some $\mathrm{T}$ cell subsets by binding to the $\mathrm{T}$ cell immunoglobulin domain and mucin domain protein 3 (Tim-3) $(13,15)$. Gal-9 is highly expressed in the liver and has diverse roles in hepatic immune homeostasis and inflammation (16). A study found that Gal-9 is released during acute falciparum malaria infection from patients of Thailand, and the plasma levels of Gal-9 reflect malaria severity (17). The increase of Tim3/Gal-9 expression levels may play an important role in the liver damage during PbANKA infection in mice (18). Kupffer cells are the predominant source of Gal-9 within the liver, and the circulating levels of Gal-9 in the plasma are elevated and Gal-9 expression is up-regulated in Kupffer cells in livers of chronic hepatitis C virus patients compared to normal controls (19).
Type I interferons (IFN-I) are a family of cytokines with a wide range of effects on innate and adaptive immune cells during infection with viruses, bacteria, parasites, and fungi (20). IFN-Iassociated responses have been reported in malaria patients (21). IFN-I-signaling mediates an inflammatory reaction in the liver, which controls parasite numbers during Plasmodium liver-stage infection, and can be either detrimental or beneficial to the host depending on host-parasite genetics during blood-stage infection (22). Plasmodium infection also triggers an IFN-I response that mediates an inflammatory reaction in the liver against liver-stage malaria parasite $(23,24)$. In addition, activation of the IFN-I pathway may contribute to the pathogenesis of cerebral malaria (25). Blockage of Gal-9/Tim-3 pathway leads to increased IFN-I production in the lung of $P b A N K A$-infected mice and murine peritoneal macrophages co-cultured with $\mathrm{PbANKA}$-infected red blood cells in vitro (26). However, so far, the mechanisms of liver histopathology in the erythrocytic stage of malaria have not been systematically studied. Therefore, the present study was designed to define the relevance and role of galectins on macrophages in $\mathrm{PbANKA}$-induced liver immunopathology in the erythrocytic stage. To analyze the role of galectin-receptor interactions in liver pathology during the erythrocytic stage of malaria, a murine model of PbANKA infection in the erythrocytic stage with or without blockage of galectin-receptor interactions were studied, here we identified a central role for galectin-receptor interactions in the survival rate, peripheral blood parasitemia/tissue parasite burden, liver pathology, and cytokine expressions in malarial mice. These findings provide the basis for developing galectinreceptor-targeted strategies to either prevent or attenuate malaria liver pathology.

\section{MATERIALS AND METHODS}

\section{Ethical Statement}

In vivo experiments were approved by the Animal Experimentation Ethics Committee of Zhongshan School of Medicine on Laboratory Animal Care at Sun Yat-sen University (No. 2016-081) and were carried out in strict accordance with the Institutional Guidelines for Care and Use of Laboratory Animals.

\section{Mice, Treatment With $\alpha$-Lactose, and Experimental Infections}

Female Kunming mice (outbred, 6-8 weeks old) were obtained from the Animal Center of Sun Yat-sen University, and PbANKA parasites were used throughout the study. Some mice were injected intraperitoneally (i.p.) with $300 \mathrm{mM}$ of $\alpha$-lactose solution in phosphate buffered saline (PBS) twice daily starting from day 1 post infection (p.i.) until the day mice were sacrificed. Animals were sacrificed using $\mathrm{CO}_{2}$ asphyxiation and the 
appropriate organs were taken for further analysis $12 \mathrm{~h}$ after the last treatment (27). A total of 48 mice were used in the experiments: 16 mice were injected i.p. with $10^{6} \mathrm{PbANKA}-$ pRBCs (e.g. malarial mice); 16 mice were injected i.p. with $10^{6}$ PbANKA-pRBCs and treated with $\alpha$-lactose; 8 mice were injected i.p. with $\alpha$-lactose alone, and 8 mice were injected with equal volume of PBS as negative controls. Mortality was monitored daily. Peripheral blood parasitemia was monitored daily by Giemsa-stained thin blood smears from the tail vein of mice. Erythrocyte counts were performed with a hematocytometer, and more than $1,000 \mathrm{RBCs}$ were counted by light microscopy $(\times 100)$ to determine the percentage of pRBCs. Eight PbANKAinfected mice were sacrificed for examination on days 5 and 7 p.i., respectively.

\section{Histopathology}

For histopathological analysis, the livers from PbANKA-infected mice, $P b$ ANKA-infected mice with $\alpha$-lactose treatment, or control mice were harvested and immediately fixed in $10 \%$ buffered formaldehyde (Guangzhou Chemical Reagent Factory, China) for $48 \mathrm{~h}$. Five-micrometer-thick sections of the organs from mice were stained with hematoxylin and eosin (H\&E) (Sigma-Aldrich, China) and evaluated for histological changes. A semi-quantitative score described previously was used to score liver inflammation and damage. Changes of the histopathological features in liver tissues were classified based on the severity of four histological criteria: architecture loss, sequestration of pRBCs in microvessels, pigment deposition, and inflammation $(4,28)$. The histopathological scores were graded on a scale of 0 to 3 [nil (0), partial loss (1), moderate loss (2), and total loss (3)]. The highest possible total score was 12 ( 4 histological criteria $\times 3$ as highest scale). Score 0 means no histopathological change and score 12 refers to the most severe histopathological change (28). Overall liver tissues were analyzed at a magnification of $\times 100$ under light microscopy by counting 10 fields of each section from each mouse in each group. All the analyses were performed by two researchers.

\section{Immunostaining for CD68 in the Livers and Morphometric Analysis}

Immunohistochemistry was carried out using the streptavidinbiotin-peroxidase complex (SABC) method. Tissue sections $(5-\mu \mathrm{m})$ were deparaffinized and rehydrated in distilled water. Heat-induced antigen retrieval was carried out in an $800-\mathrm{W}$ microwave oven for $30 \mathrm{~min}$. Endogenous peroxidase activity was blocked by incubation with $3 \%$ hydrogen peroxide in methanol for $10 \mathrm{~min}$ at $37^{\circ} \mathrm{C}$. Nonspecific binding was blocked by incubation in $5 \%$ bovine serum albumin (Sigma-Aldrich) in PBS ( $\mathrm{pH} 7.4$ ) for 10 $\mathrm{min}$ at room temperature. The sections were incubated with rabbit anti-CD68 (Wuhan Boster Biological Engineering Co., Ltd., Wuhan, China) (1:200 dilutions) overnight at $4^{\circ} \mathrm{C}$, and then with secondary antibodies. Sections incubated with secondary antibodies only were used as isotype controls. Signals were detected with a SABC kit and developed in diaminobenzidine tetrahydrochloride (Zhongshan Golden Bridge Technology, Beijing, China). The sections were counterstained with hematoxylin and examined under a light microscope. $\mathrm{CD}^{+} 8^{+}$macrophages were identified by dark-brown staining and were quantified using images captured with a digital camera system and analyzed by using Image-Pro Plus (Image Z1 software, Media Cybernetics, MD, USA). The number of cells in each field was determined under high power field as well as the area of each field $\left(0.015066 \mathrm{~mm}^{2}\right)$. The density of positive cells was expressed as the number of cells per square millimeter.

\section{Immunofluorescence Assay}

For primary antibody incubation, liver tissues were incubated with mouse anti-mouse CD68 monoclonal antibody (IgG1; 1:200; Abcam, Cambridge, UK) and rabbit anti-Tim-3 polyclonal antibody (IgG1; 1:200 dilution; Abcam) or rabbit anti-Gal-9 monoclonal antibody (IgG1; 1:200 dilution; Bioss, Beijing, China) overnight at $4^{\circ} \mathrm{C}$. Subsequently, PBS ( $\left.\mathrm{pH} 7.4\right)$ washed sections were incubated with anti-mouse $\operatorname{IgG}(\mathrm{H}+\mathrm{L}), \mathrm{F}$ $(\mathrm{ab})_{2}$ fragment (Alexa Fluor. 488 Conjugate) $(2 \mathrm{mg} / \mathrm{ml}, 1: 200$ dilution; Cell Signaling Technology, MD, USA) or anti-rabbit $\operatorname{IgG}(\mathrm{H}+\mathrm{L}), \mathrm{F}(\mathrm{ab})_{2}$ fragment (Alexa Fluor. 555) $(2 \mathrm{mg} / \mathrm{ml}, 1: 200$ dilution; Cell Signaling Technology) for $1 \mathrm{~h}$ at room temperature in a dark chamber. After washing 3 times with PBS, the slides were mounted with polyvinylpyrrolidone antifade mounting medium (Beyotime, Haimen, China) with DAPI (1: 50,000; Sigma-Aldrich) in a dark chamber. For negative controls, a set of liver tissue slides was incubated under similar conditions without the primary antibodies. $\mathrm{CD} 68^{+}$-macrophages were identified by their green fluorescence in liver, whereas Tim $-3^{+}$ and Gal $-9^{+}$cells were identified by their red fluorescence, once CD68 and Gal-9 or CD68 and Tim-3 superimposed in one image that would appear as yellow fluorescence under a fluorescence microscope (Olympus BX63, Tokyo, Japan). Two researchers performed the observations.

\section{TUNEL Staining}

Formalin-fixed paraffin embedded liver tissue sections $(5-\mu \mathrm{m})$ were detected using TUNEL assay (Wuhan Boster Biological Engineering Co., Ltd.). Negative control was prepared by omission of terminal deoxynucleotidyl transferase. Apoptotic cells were determined under high power field as well as the area of each field $\left(0.015066 \mathrm{~mm}^{2}\right)$. The density of positive cells was expressed as the number of cells per square millimeter.

\section{Isolation of Murine Primary Peritoneal Macrophages}

Female Kunming mice were used in this study. Naive mice, mice with $\alpha$-lactose treatment, and PbANKA-infected mice with or without $\alpha$-lactose treatment on day 5 p.i. were injected i.p. with 2 $\mathrm{ml} \mathrm{3 \%}$ thioglycollate broth (Sigma-Aldrich) solution in PBS once daily for 3 days. Animals were sacrificed and their peritoneal lavage fluid were spun at $800 \mathrm{~g}$ at $4^{\circ} \mathrm{C}$ for $5 \mathrm{~min}$, and the pelleted peritoneal macrophages were re-suspended and seeded at $5 \times 10^{5}$ cells/well in 12-well plates (Corning, NY, USA). After $4 \mathrm{~h}$ at $37^{\circ} \mathrm{C}$ in a $5 \% \mathrm{CO}_{2}$ atmosphere, cells were washed and isolated. Samples were stored at $-80^{\circ} \mathrm{C}$ until subjected to further analysis.

\section{Transmission Electron Microscopy}

The peritoneal macrophages from PbANKA-infected mice, $P b$ ANKA-infected mice with $\alpha$-lactose treatment, or control 
mice were isolated by centrifugation at $1000 \mathrm{~g}$ for $3 \mathrm{~min}$. The precipitates were immediately fixed in 3\% glutaraldehyde and $1 \%$ osmium tetroxide (both in $100 \mathrm{mM}$ PBS, $\mathrm{pH}$ 7.2) overnight before being dehydrated through a series of graded ethanol solutions. The fixed tissues were then embedded in SPIPon 812 Embedding Kit (Structure Probe Inc., West Chester, PA, USA) following the manufacture's instruction. Ultrathin sections (70 $\mathrm{nm}$ ) were cut from the embedded tissues using the Leica EM UC6 ultramicrotome (Leica Microsystems, Wetzlar, Germany) and mounted on formvar-coated grids. The sections were then stained for $15 \mathrm{~min}$ in aqueous $1 \%$ uranyl acetate followed by $0.2 \%$ lead citrate, and were then analyzed under a JEM100CX-II transmission electron microscope (JEOL Ltd., Tokyo, Japan) at an accelerating voltage of $100 \mathrm{kV}$.

\section{Measurement of mRNA Expression by Using Quantitative Real-Time Reverse Transcription-Polymerase Chain Reaction (qRT-PCR) Assay}

Total RNA was extracted from about $100 \mathrm{mg}$ of mouse liver and spleen tissues or peritoneal macrophages of each group using a commercial RNA Extraction Kit (TaKaRa Bio Inc., Shiga, Japan) according to the manufacturer's protocol. The quality of total RNA was analyzed by running $5 \mu \mathrm{l}$ of each RNA sample on a $1.0 \%$ agarose gel stained with ethidium bromide. The quantity of total RNA was estimated by measuring the ratio of absorbance at 260 and $280 \mathrm{~nm}$ using a NanoDrop ND-1000 spectrophotometer (NanoDrop Technologies, DE, USA). First-strand cDNA was constructed from $1.0 \mu \mathrm{g}$ of total RNA with oligo (dT) as primers using a PrimeScript ${ }^{\text {TM }}$ II 1st Strand cDNA Synthesis Kit (TaKaRa Bio Inc.) following the manufacturer's protocol, and cDNA was stored at $-80^{\circ} \mathrm{C}$ until use. To determine the mRNA levels of IFN $\alpha$, IFN $\beta$, IFN $\gamma$, TREM-1, TREM-2, Gal-9, and Tim-3 in tissues or macrophages of different groups of mice, qRT-PCR was performed using SYBR Green QPCR Master Mix (TaKaRa Bio Inc.) according to the manufacturer's instructions. For liver parasite burden, mRNA level of PbANKA $18 \mathrm{~S}$ rRNA measured by qRT-PCR is shown as $-\Delta \Delta$ Ct values. Primers for the qRT-PCR are listed in Table 1. Briefly, a total of $10 \mu$ reaction mixture contained $5.0 \mu$ l of SYBR ${ }^{\circledR}$ Premix Ex TaqTM $(2 \times), 0.5 \mu$ l of each primer $(10 \mathrm{pM}), 3.0 \mu \mathrm{l}$ of $\mathrm{dH}_{2} \mathrm{O}$, and $1.0 \mu \mathrm{l}$ of cDNA $(0.2 \mu \mathrm{g} / \mu \mathrm{l})$. Amplification was pre-denaturized for $30 \mathrm{~s}$ at $95^{\circ} \mathrm{C}$ followed by 43 cycles of $5 \mathrm{~s}$ at $95^{\circ} \mathrm{C}$ and $20 \mathrm{~s}$ at $60^{\circ} \mathrm{C}$ with a LightCycler ${ }^{\circledR} 480$ instrument (Roche Diagnostics, AL, USA). Specific mRNA expression levels were normalized to that of the housekeeping gene, $\beta$-actin, and the results are expressed as fold change compared with uninfected controls (with or without $\alpha$-lactose treatment).

\section{Statistical Analysis}

Results of experimental studies were reported as mean \pm SD. Statistical analysis of the data was performed using Wilcoxon rank sum test, Student's $t$-test, and one-way ANOVA followed by Bonferoni's multiple comparison tests using SPSS software for windows (version 19.0; SPSS Inc., Chicago, IL, USA). All graphs were performed using GraphPad Prism software and a value of $P<0.05$ was considered statistically significant.

\section{RESULTS}

\section{Blockage of Galectin-Receptor Interactions Decreased the Survival Rate and Increased Peripheral Blood Parasitemia/Tissue Parasite Burden in PbANKA-Infected Mice}

Malarial mice died between 7 and 12 days p.i., while malarial mice treated with $\alpha$-lactose died between 6 and 10 days p.i. (Figure 1A). Malarial mice treated with $\alpha$-lactose developed a significantly higher peripheral blood parasitemia on days $5(P<$ $0.01), 6(P<0.01), 7(P<0.001)$, and $8(P<0.01)$ p.i. compared with those of malarial mice (Figure 1B). In addition, measured by using qRT-PCR, there were significantly increased parasite burdens (PbANKA 18S rRNA) in the livers of malarial mice treated with $\alpha$-lactose compared with those of malarial mice on days $5(P<0.001)$ and $7(P<0.05)$ p.i. (Figure 1C). Thus, blockage of galectin-receptor interactions increased peripheral blood parasitemia and tissue parasite burden, and shortened the survival of mice after PbANKA infection.

\section{Blockage of Galectin-Receptor Interactions Increased Liver Damage of PbANKA-Infected Mice}

Histopathological analysis showed no obvious morphological changes in the liver tissues of uninfected mice and uninfected mice treated with $\alpha$-lactose. However, on days 5 and 7 p.i.,

TABLE 1 | Primer sequences of genes used for quantitative real-time reverse transcription-polymerase chain reaction assay.

\begin{tabular}{|c|c|c|c|}
\hline Genes & Forward primer $\left(5^{\prime} \rightarrow 3^{\prime}\right)$ & Reverse primer $\left(5^{\prime} \rightarrow 3^{\prime}\right)$ & Accession \\
\hline IFN $\alpha$ & CTTGGATTCCCGCAGGA & TGTAGGACAGGGATGGCTTGA & NC_000070.6 \\
\hline Gal-9 & GTTGTCCGAAACACTCAGAT & ATATGATCCACACCGAGAAG & NC_000077.6 \\
\hline Tim-3 & CCACGGAGAGAAATGGTTC & CATCAGCCCATGTGGAAAT & NC_000077.6 \\
\hline TREM-1 & GACTGCTGTGCGTGTTCTTTG & GCCAAGCCTTCTGGCTGTT & NC_000083.6 \\
\hline
\end{tabular}


A
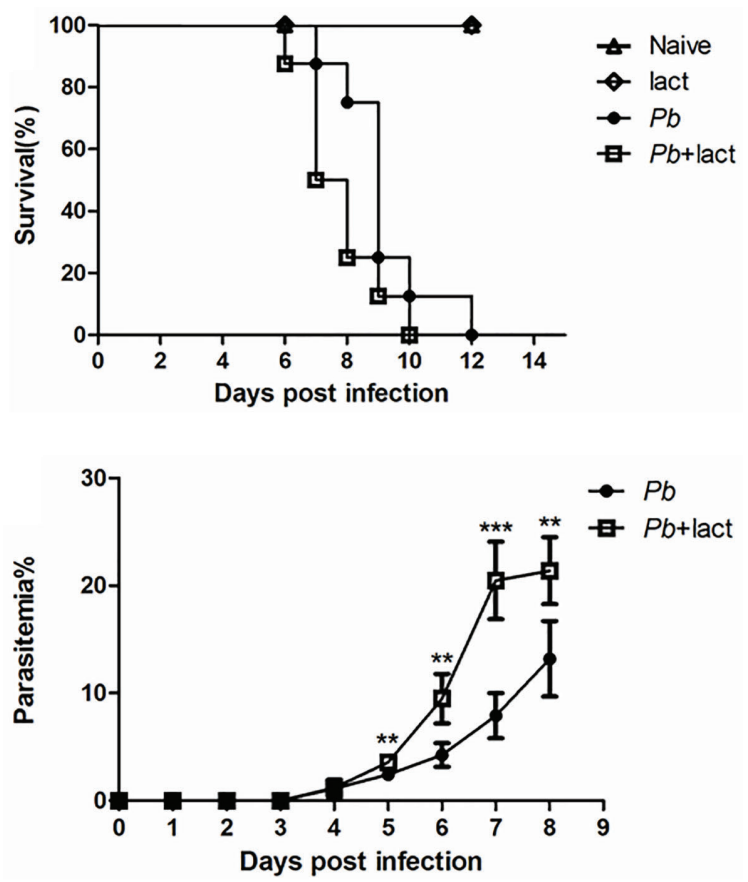

C

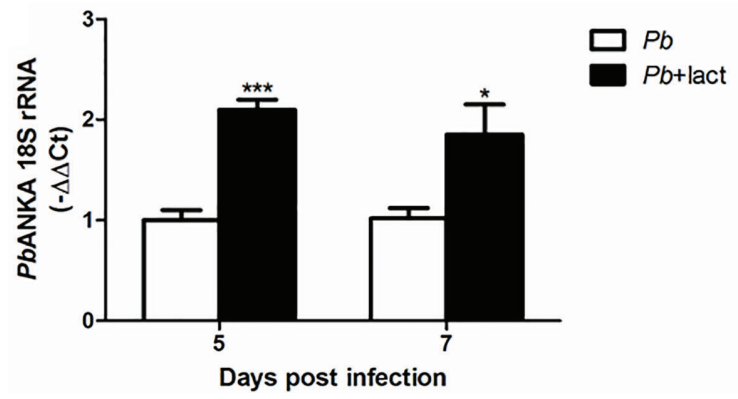

FIGURE 1 | Survival rate, peripheral blood parasitemia, and liver parasite burden in PbANKA-infected mice with or without $\alpha$-lactose treatment. (A) Survival rate. Malarial mice $(n=8)$ died between days 7 and 12 p.i. Malarial mice treated with $\alpha$ lactose $(n=8)$ died between days 6 and 10 p.i. (B) Peripheral blood parasitemia levels of malarial mice and malarial mice treated with $\alpha$-lactose were determined through blood smears at the indicated time points. Parasitemia are shown as mean \pm SD. ${ }^{* *} P<0.01$, malarial mice treated with $\alpha$-lactose on days 5,6 , and 8 p.i. vs. malarial mice on days 5,6 , and 8 p.i.; ${ }^{* \star *} P<0.001$, malarial mice treated with $\alpha$-lactose on day 7 p.i. vs. malarial mice on day 7 p.i. There were 4 mice per group, and data are representative of those from two experiments. (C) Parasite burden estimated using mRNA level of PbANKA 18S rRNA in the livers was measured by using qRT-PCR. Values are means from triplicate measurements, and data are shown as $-\Delta \Delta$ Ct values. ${ }^{* *} P<0.001$, malarial mice with $\alpha$-lactose treatment on day 5 p.i. vs. malarial mice on day 5 p.i.; ${ }^{*} P<0.05$, malarial mice with $\alpha$-lactose treatment on day 7 p.i. vs. malarial mice on day 7 p.i. There were 4 mice per group, and data are representative of those from two experiments.

obvious inflammation and necrotic lesions (indicated with green arrow heads) were observed in the livers of both malarial mice and malarial mice treated with $\alpha$-lactose. Furthermore, extensive malarial pigment deposition was observed in the livers of malarial mice on day 5 p.i. and in the livers of malarial mice treated with $\alpha$-lactose on days 5 and 7 p.i. (Figure 2A). Semiquantitative inflammation scores based on pathological changes of the liver tissues showed that compared with malarial mice, significantly increased histopathological scores in the livers of malarial mice with $\alpha$-lactose treatment on days $5(P<0.05)$ and 7 $(P<0.01)$ p.i. Compared with day 5 p.i., there were significantly increased histopathological scores in the livers of both malarial mice and malarial mice with $\alpha$-lactose treatment on day 7 p.i. $(P<0.01)$ (Figure 2B). The data suggested that more severe liver pathology developed in malarial mice with $\alpha$-lactose treatment than that in malarial mice.

\section{Blockage of Galectin-Receptor Interactions Enhanced Apoptosis in the Livers of PbANKA-Infected Mice}

Apoptosis in the livers was measured by TUNEL staining. There were only a few apoptotic cells observed in the liver tissues of uninfected controls. On days 5 and 7 p.i., a great number of apoptotic cells were observed in the livers of both malarial mice and malarial mice treated with $\alpha$-lactose. However, more apoptotic cells, scattered throughout the liver tissue section, were observed in the livers of malarial mice treated with $\alpha$ lactose in comparison of those of malarial mice on days 5 and 7 p.i. (Figure 3A). Quantitative analysis of TUNEL positive cells showed that compared with uninfected controls, the numbers of apoptotic cells were significantly increased in the livers of malarial mice with or without $\alpha$-lactose treatment on days 5 and 7 p.i. $(P<0.001)$. Compared with malarial mice, the numbers of apoptotic cells were significantly increased in the livers of malarial mice treated with $\alpha$-lactose on days $5(P<0.01)$ and $7(P<0.001)$ p.i. (Figure 3B). Phagocytosis of pRBCs causes induction of apoptosis in macrophages through release of cytosolic factors from $P$. falciparum 3D7-infected mouse macrophages (29). The data demonstrated that blockage of galectin-receptor interactions may increase cellular apoptosis in the liver during the erythrocytic stage of malaria.

\section{Blockage of Galectin-Receptor Interactions Increased CD68 ${ }^{+}$ Macrophages in the Livers of PbANKA-Infected Mice}

A few $\mathrm{CD}^{+} 8^{+}$macrophages (brown color) were observed in the liver tissues of uninfected controls. However, a large number of $\mathrm{CD}^{+} 8^{+}$ macrophages were dispersed in the liver sections of malarial mice or malarial mice treated with $\alpha$-lactose on days 5 and 7 p.i. (Figure 4A). Quantitative analysis of $\mathrm{CD}^{+} 8^{+}$macrophages in the liver tissues showed that compared with uninfected controls, there were significantly higher numbers of $\mathrm{CD}^{+} 8^{+}$macrophages in the livers of malarial mice on days 5 and 7 p.i. $(P<0.001)$. Compared with malarial mice, there were significantly increased $\mathrm{CD} 68^{+}$macrophages in the livers of malarial mice with $\alpha$-lactose treatment on days 5 and 7 p.i. $(P<0.001)$. Compared with malarial mice or malarial mice with $\alpha$-lactose treatment on day 5 p.i., there were significantly increased numbers of $\mathrm{CD}^{+} 8^{+}$macrophages in the livers of malarial mice and malarial mice with $\alpha$-lactose treatment on day 7 p.i. $(P<0.01$ and $P<$ 0.05 , respectively) (Figure $4 B$ ). It has been reported that the number 


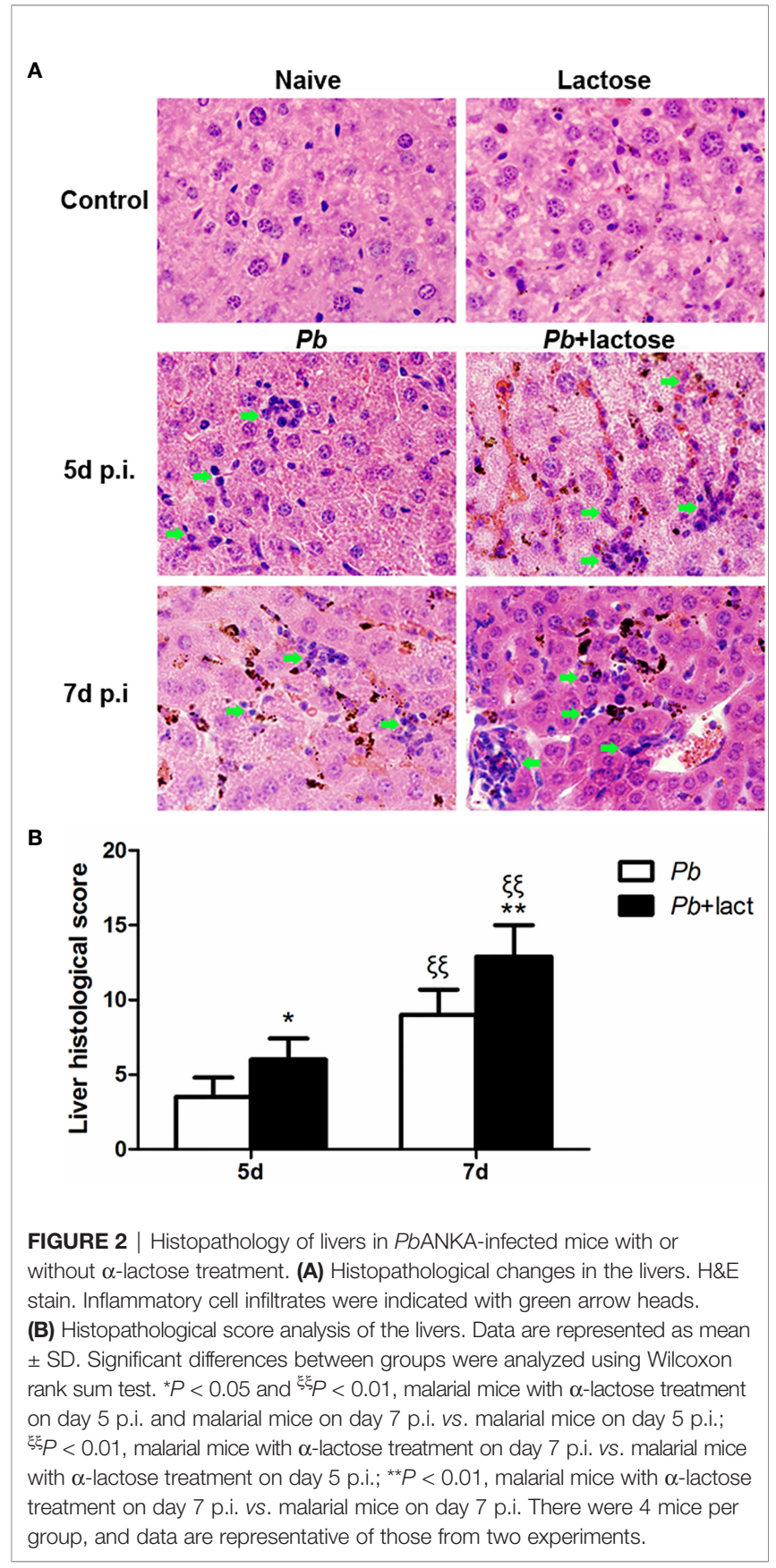

of Kupffer cells is significantly increased and their phagocytic activity is enhanced during the erythrocytic stage of malaria in SpragueDawley rats infected with PbANKA (30). In addition, Kupffer cells show marked hypertrophy and hyperplasia and are filled with malarial pigment, and total Kupffer cell phagocytic activity in the liver during the erythrocytic phase of malaria is also markedly increased in Wistar rats infected with PbANKA (31). Our data indicate that blockage of galectin-receptor interactions may increase the activity of liver $\mathrm{CD}^{-} 8^{+}$macrophages in the erythrocytic stage of malaria, which is in agreement with the increased parasitemia and tissue parasite burden in malarial mice with $\alpha$-lactose treatment.

A

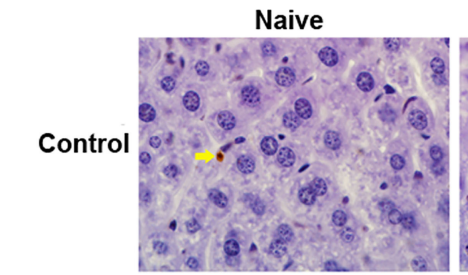

$\mathrm{Pb}$

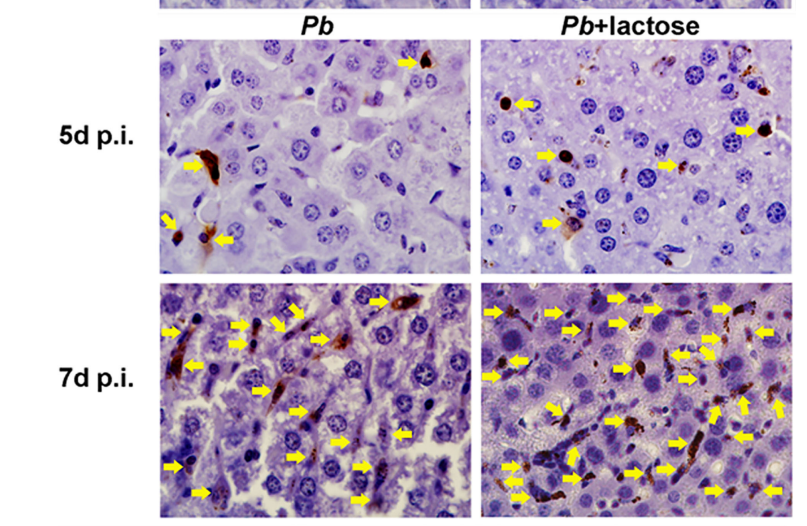

B

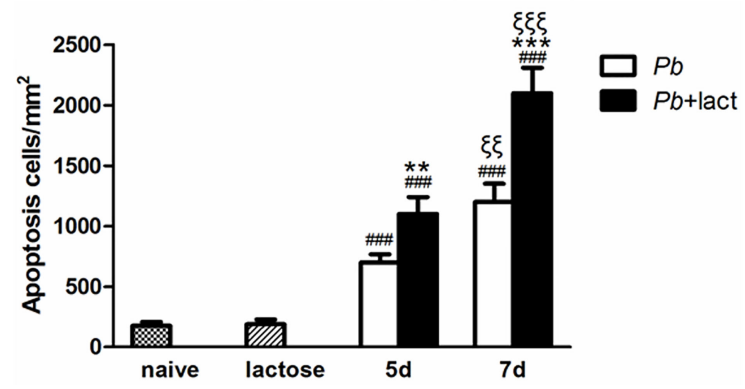

FIGURE 3 | TUNEL staining of the liver tissues of PbANKA-infected mice with or without $\alpha$-lactose treatment. Shown are representative liver sections by using TUNEL staining. (A) Apoptotic cells in the livers of naive mice, mice with $\alpha$-lactose treatment, malarial mice, and malarial mice with $\alpha$-lactose treatment on days 5 and 7 p.i. Apoptotic cells were indicated with yellow arrow heads. Original magnification $\times 1,000$. (B) Morphometric analysis of apoptotic cells in the liver tissues. Shown are apoptotic cells per square millimeter. Data are presented as means \pm SD; experiments were performed with 4 mice per group. ${ }^{\# \# ~} P<0.001$, malarial mice on day 5 p.i., malarial mice with $\alpha$-lactose treatment on day 5 p.i., malarial mice on day 7 p.i., and malarial mice with $\alpha$-lactose treatment on day 7 p.i. vs. naive group; ${ }^{\star \star} P<0.01$, malarial mice with $\alpha$-lactose treatment on day 5 p.i. vs. malarial mice on day 5 p.i.; ${ }^{\xi \xi} P<0.001$, malarial mice with $\alpha$-lactose treatment on day 7 p.i. vs. malarial mice with $\alpha$-lactose treatment on day 5 p.i.; ${ }^{\star \star \star} P<0.001$, malarial mice with $\alpha$-lactose treatment on day 7 p.i. vs. malarial mice on day 7 p.i. ${ }^{\xi} p<0.01$, malarial mice on day 7 p.i. vs. malarial mice on day 5 p.i.

\section{Gal-9 and Tim-3 Expressions on $\mathrm{CD}^{+}{ }^{+}$Macrophages in the Livers After PbANKA Infection}

Immunofluorescence assay showed that both Gal-9 (Figure 5A) and Tim-3 (Figure 5B) were expressed on the $\mathrm{CD} 68^{+}$macrophages in the liver tissues of all the groups; more $\mathrm{CD} 68^{+}-\mathrm{Gal}-9^{+}$and $\mathrm{CD} 68^{+}$-Tim $-3^{+}$macrophages were observed in malarial mice and malarial mice treated with $\alpha$-lactose in comparison of uninfected controls. The data suggested that $\mathrm{CD} 68^{+}-\mathrm{Gal}-9^{+}$and $\mathrm{CD} 68^{+}-\mathrm{Tim}-$ 


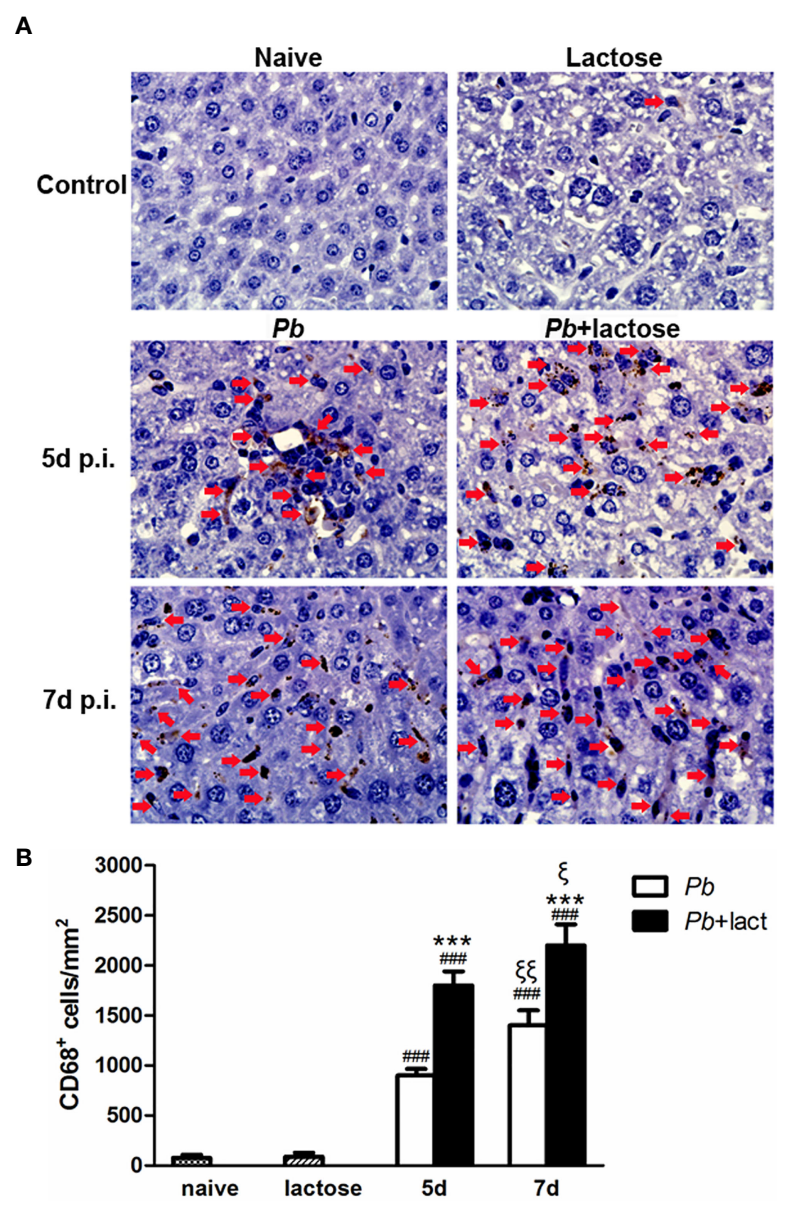

FIGURE 4 | Immunohistochemical staining for $\mathrm{CD}^{2} 8^{+}$macrophages in the livers of PbANKA-infected mice with or without $\alpha$-lactose treatment. (A) Immunohistochemical staining of $\mathrm{CD}^{+} 8^{+}$macrophages in the livers of uninfected mice, uninfected mice with $\alpha$-lactose treatment, malarial mice, and malarial mice with $\alpha$-lactose treatment on day 7 p.i. Positive cells were indicated with red arrow heads. Original magnification $\times 1,000$. (B) Morphometric analysis of liver tissues. Shown are $\mathrm{CD} 8^{+}$macrophages per square millimeter. Data are presented as means \pm SD; experiments were performed with three mice per group. ${ }^{\# \#} P<$ 0.001 , malarial mice on day 5 p.i., malarial mice with $\alpha$-lactose treatment on day 5 p.i., malarial mice on day 7 p.i., and malarial mice with $\alpha$-lactose treatment on day 7 p.i. vs. naive group; ${ }^{\star \star \star} P<0.001$, malarial mice with $\alpha$-lactose treatment on day 5 p.i. vs. malarial mice on day 5 p.i.; ${ }^{\star \star \star} P<0.001$, malarial mice with $\alpha$-lactose treatment on day 7 p.i. vs. malarial mice on day 7 p.i.; ${ }^{\xi} P<0.05$, malarial mice with $\alpha$-lactose treatment on day 7 p.i. vs. malarial mice with $\alpha$-lactose treatment on day 5 p.i.; ${ }^{{ }^{\xi}} \mathrm{P}<0.01$, malarial mice on day 7 p.i. vs. malarial mice on day 5 p.i.

$3^{+}$macrophages play a role in the inflammatory response in liver during the erythrocytic stage of malaria.

\section{Blockage of Galectin-Receptor Interactions Enhanced Gal-9, Tim-3, IFN $\alpha$, IFN $\gamma$, and TREM-1 Expressions in the Livers or Spleens of PbANKA-Infected Mice}

Here, the mRNA expression levels of Gal-9, Tim-3, IFN $\alpha$, IFN $\beta$, IFN $\gamma$, TREM-1, and TREM-2 in the livers and spleens of PbANKA-infected mice with or without $\alpha$-lactose treatment on day 7 p.i. were examined (Figure 6). Compared with uninfected controls, there were significantly increased Gal-9 $(P<0.05$ and $P<0.001$, respectively) and Tim-3 $(P<0.01$ and $P<0.001$, respectively) in the livers, and significantly increased Gal-9 $(P<0.001)$ and Tim-3 $(P<0.01)$ in the spleens of malarial mice and malarial mice with $\alpha$-lactose treatment on day 7 p.i. Compared with malarial mice, there were significantly increased mRNA levels of Gal-9 and Tim-3 in the livers of malarial mice with $\alpha$-lactose treatment on day 7 p.i. $(P<0.01)$.

Compared with uninfected controls, there were significantly increased mRNA expression levels of IFN $\alpha(P<0.01$ and $P<$ 0.001 , respectively), IFN $\gamma(P<0.001)$, and TREM- $1(P<0.05$ and $P<0.001$, respectively) in the livers, and significantly increased levels of IFN $\alpha(P<0.01)$, IFN $\gamma(P<0.001)$, and TREM-1 $(P<$ $0.001)$ in the spleens of malarial mice and malarial mice with $\alpha$ lactose treatment on day 7 p.i. Compared with malarial mice, there were significantly increased levels of IFN $\alpha(P<0.01)$, IFN $\gamma$ $(P<0.001)$, and TREM-1 $(P<0.05)$ in the livers and significantly increased TREM-1 level $(P<0.05)$ in the spleens of malarial mice with $\alpha$-lactose treatment on day 7 p.i.

\section{Ultrastructural Observation of Peritoneal Macrophages by Transmission Electron Microscopy}

The ultrastructures of peritoneal macrophages isolated from different groups of mice were observed by transmission electron microscopy, the peritoneal macrophages from PbANKA-infected mice with $\alpha$-lactose treatment showed more pseudopodia in comparison of those from PbANKA-infected mice (Figure 7).

\section{Blockage of Galectin-Receptor Interactions Increased Gal-9, Tim-3, IFN $\alpha$, IFN $\beta$, IFN $\gamma$, and TREM-1 Expressions in the Peritoneal Macrophages Isolated From PbANKA-Infected Mice}

To test whether galectin-receptor interactions have an impact on functional activation of macrophages by $\mathrm{PbANKA}$ infection, we examined the mRNA expression levels of Gal-9, Tim-3, IFN $\alpha$, IFN $\beta$, IFN $\gamma$, TREM-1, and TREM- 2 in the peritoneal macrophages ex vivo isolated from $P b A N K A$-infected mice with or without $\alpha$-lactose treatment on day 7 p.i. Compared with uninfected controls, there were significantly increased levels of Gal-9 $(P<0.05$ and $P<0.001$, respectively), Tim-3 $(P<0.05)$, IFN $\alpha(P<0.01$ and $P<0.001$, respectively), IFN $\beta(P<0.01$ and $P<0.001$, respectively), IFN $\gamma(P<0.01$ and $P<0.001$, respectively), and TREM- $1(P<0.001)$ in the peritoneal macrophages isolated from both $P b A N K A$-infected mice and PbANKA-infected mice treated with $\alpha$-lactose. Compared with $P b A N K A$-infected mice, there were significantly increased levels of Gal-9 $(P<0.05)$, IFN $\alpha(P<0.05)$, IFN $\beta(P<0.05)$, IFN $\gamma(P<$ $0.01)$, and TREM-1 $(P<0.001)$ in those from $P b$ ANKA-infected mice treated with $\alpha$-lactose (Figure 8). Studies has revealed a substantial deleterious role for IFN-I-signaling in mediating severe and lethal disease during PbANKA infection (22). IFN- $\gamma$ 
A

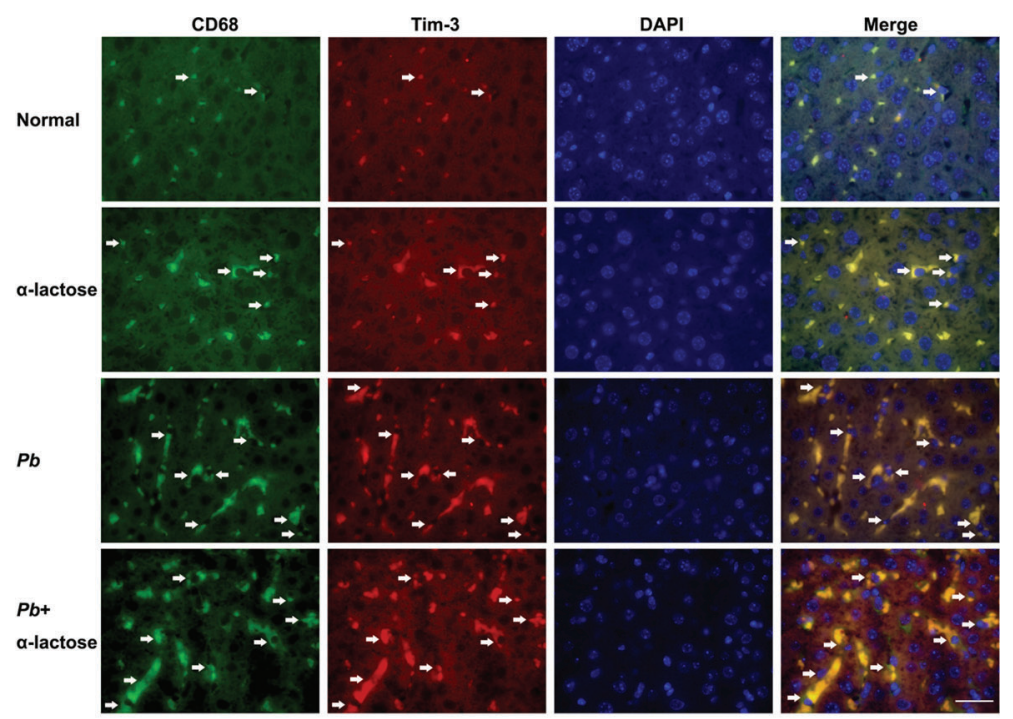

B

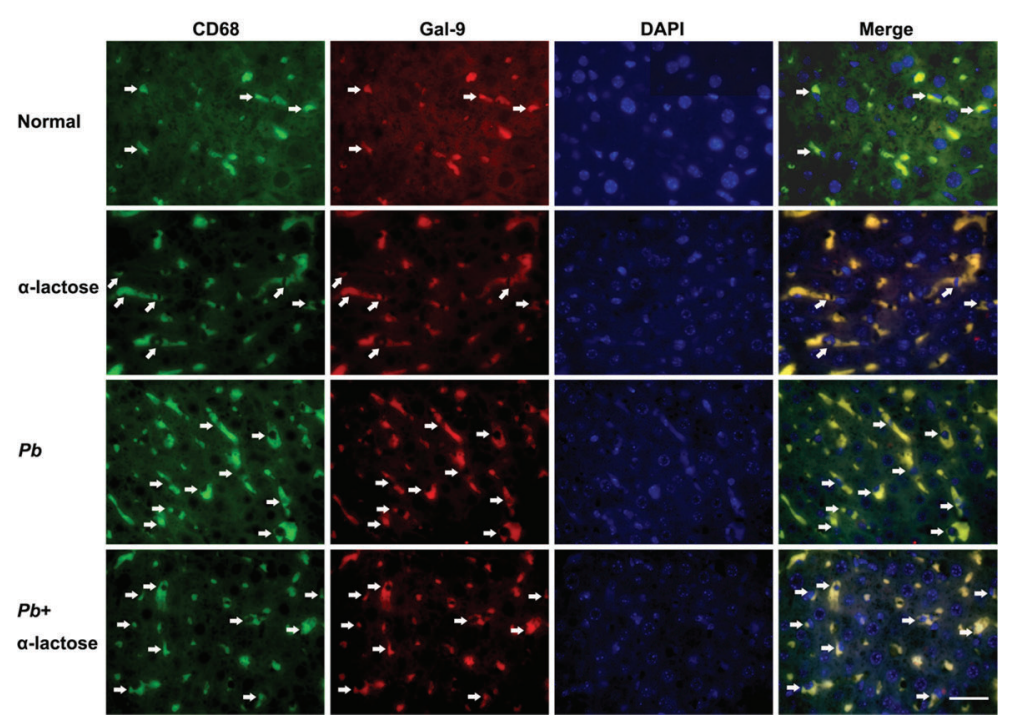

FIGURE 5 | Immunofluorescence staining for $\mathrm{CD} 68^{+}-\mathrm{Gal}-9^{+}$and $\mathrm{CD} 68^{+}-\mathrm{Tim}-3^{+}$macrophages in the liver tissues of PbANKA-infected mice with or without $\alpha$-lactose treatment. Double immunofluorescence showed expression of Gal-9 or Tim-3 on CD68 ${ }^{+}$macrophages. (A) CD68 ${ }^{+}-\mathrm{Gal}_{-} \mathrm{9}^{+}$macrophages in the liver tissues of malarial mice and malarial mice with $\alpha$-lactose treatment on day 7 p.i. (B) CD68 $8^{+}-$Tim- $3^{+}$macrophages in the liver tissues of malarial mice and malarial mice with $\alpha$-lactose treatment on day 7 p.i. in comparison of naive and $\alpha$-lactose-control. Positive cells were indicated with white arrow heads. Original magnification $\times 1,000$.

is a key contributor to the pathogenesis of cerebral malaria in the PbANKA mouse model (32). Using PbANKA-infected ICR mice to investigate the involvement of TREM-1 during malaria infection, and found that mice with low parasitemia levels have low concentrations of plasma TREM-1 and vice versa. Therefore, TREM-1 plays important pro-inflammatory roles during malaria infection and may be one of the key mediators of the disease's severity (33). The data suggested that blockage of galectinreceptor interactions induces the expressions of IFN-I, IFN $\gamma$, and TREM-1 genes, which may exacerbate liver damage of malarial mice.

\section{Correlations Between Gal-9/Tim-3 and IFN $\alpha$, IFN $\beta$, IFN $\gamma$, or TREM-1 Expression Levels In Vivo and Ex Vivo}

The correlations between the mRNA levels of Gal-9 and Tim-3/ IFN $\alpha /$ IFN $\beta /$ IFN $\gamma /$ TREM- 1 in the livers, spleens, and peritoneal macrophages of $\mathrm{PbANKA}$-infected mice or PbANKA-infected mice treated with $\alpha$-lactose were evaluated, and only significant correlations were presented. There were significant correlations between the mRNA levels of Gal-9 and Tim-3 ( $\mathrm{r}=0.9966, P=$ $0.0034)$, Gal-9 and IFN $\gamma(\mathrm{r}=0.9922, P=0.0078)$, and Gal-9 and TREM-1 ( $\mathrm{r}=0.9847, P=0.0153$ ) in the livers of PbANKA- 
A

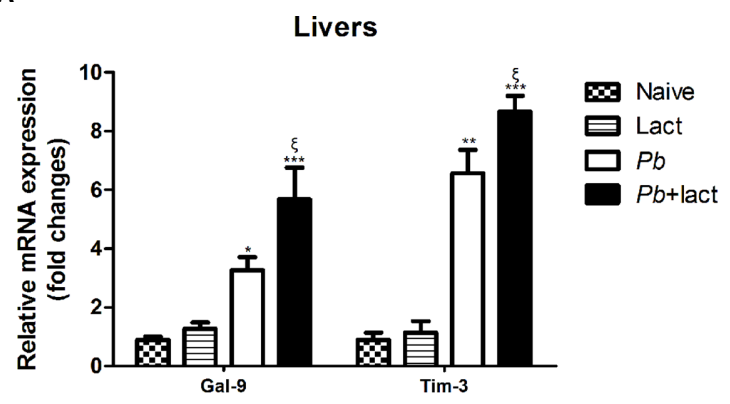

B

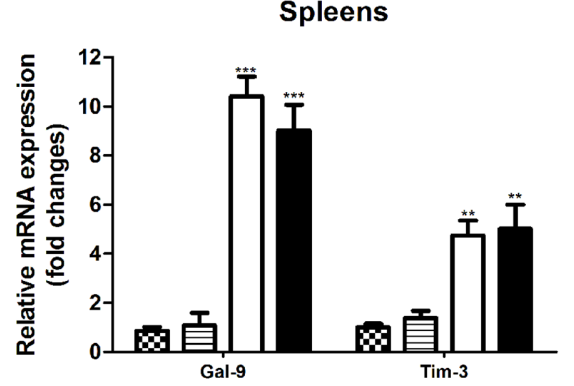

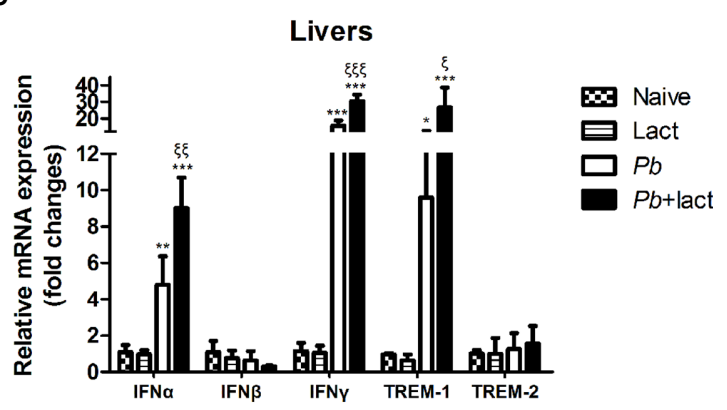

D

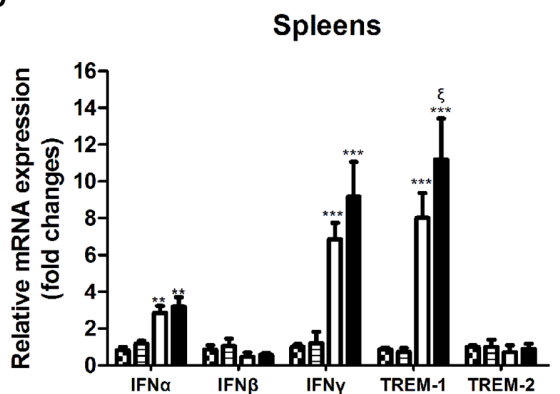

FIGURE 6 | Relative mRNA expressions of Gal-9, Tim-3, IFN $\alpha$, IFN $\beta$, IFN $\gamma$, TREM-1, and TREM-2 in the liver (A, C) and spleen (B, D) tissues of PbANKA-infected mice with or without $\alpha$-lactose treatment were detected by using qRT-PCR. Values are means from triplicate measurements, and data are presented as means \pm SD; two independent experiments were performed with 4 mice per group. ${ }^{*} P<0.05,{ }^{* *} P<0.01$, and ${ }^{* \star} P<0.001, \alpha$-lactose-control, malarial mice on day 7 p.i., and malarial mice with $\alpha$-lactose treatment on day 7 p.i. vs. naive mice; ${ }^{\xi} P<0.05$, ${ }^{{ }^{\xi}} P<0.01$, and ${ }^{{ }^{\xi} \xi \xi} P<0.001$, malarial mice with $\alpha$-lactose treatment on day 7 .i. vs. malarial mice on day 7 p.i.

infected mice (Figure 9A), and there was significant correlation between the mRNA levels of Gal-9 and IFN $\gamma(\mathrm{r}=0.9839, P=$ $0.0161)$ in the livers of PbANKA-infected mice treated with $\alpha$ lactose (Figure 9B). There were significant correlations between the mRNA levels of Gal-9 and IFN $\gamma(\mathrm{r}=0.9947, P=$ $0.0053)$, and Gal-9 and TREM-1 $(\mathrm{r}=0.9918, P=0.0882)$ in the spleens of PbANKA-infected mice (Figure 9C). There were significant correlations between the mRNA levels of Gal-9 and Tim-3 ( $\mathrm{r}=0.9642, P=0.0396)$, Gal-9 and IFN $\gamma(\mathrm{r}=0.9822, P=$ $0.0239)$, and Gal-9 and TREM- $1(r=0.9998, P=0.0069)$ in the peritoneal macrophages isolated from $\mathrm{PbANKA}$-infected mice (Figure 9D), and there was significant correlation between the mRNA levels of Gal-9 and IFN $\alpha(r=0.9225, P=0.0451)$ in the peritoneal macrophages isolated from $\mathrm{PbANKA}$-infected mice treated with $\alpha$-lactose (Figure 9E). Taken together, significant positive correlations existed between the mRNA levels of Gal-9 and Tim-3/IFN $\gamma /$ TREM-1 in both the livers and peritoneal macrophages, and between Gal-9 and Tim-3/TREM-1 in the spleens of $\mathrm{PbANKA}$-infected mice; significant positive correlations existed between the mRNA levels of Gal-9 and IFN $\gamma$ in the livers and between Gal-9 and IFN $\alpha$ in the peritoneal macrophages from $\mathrm{PbANKA}$-infected mice treated with $\alpha$-lactose. The data suggested that Gal-9/Tim-3 pathway may play an important role in the regulation of liver inflammatory response including upregulation of TREM-1,
IFN $\gamma$, and IFN $\alpha$ expressions during the erythrocytic stage of PbANKA infection.

\section{DISCUSSION}

Hepatic dysfunction is one of the clinical features in severe falciparum malaria and a significant cause of morbidity and mortality among humans (4). However, the immunoregulatory mechanisms of hepatic injury during malaria are still poorly understood. To analyze the impact of galectin-receptor interactions on malaria-induced liver pathology, we employed $P b A N K A$ infection in a murine model. Our data showed that mice infected with $P b A N K A$ plus $\alpha$-lactose treatment had lower survival rate, increased peripheral blood parasitemia and parasite burdens in the liver, more severe hepatocyte damage, and increased apoptotic cells in the liver compared with those of malarial mice. Moreover, our data found that the expression levels of Gal-9, Tim-3, IFN $\alpha$, IFN $\beta$, IFN $\gamma$, and TREM-1 were more upregulated in the livers, spleens, and peritoneal macrophages of malarial mice with $\alpha$-lactose treatment relative to those of malarial mice without $\alpha$-lactose treatment.

It has been documented that the liver serves as an effector against blood-stage malaria (34), wherein the liver endothelial system eliminates the parasitized erythrocytes possibly by phagocytosis 

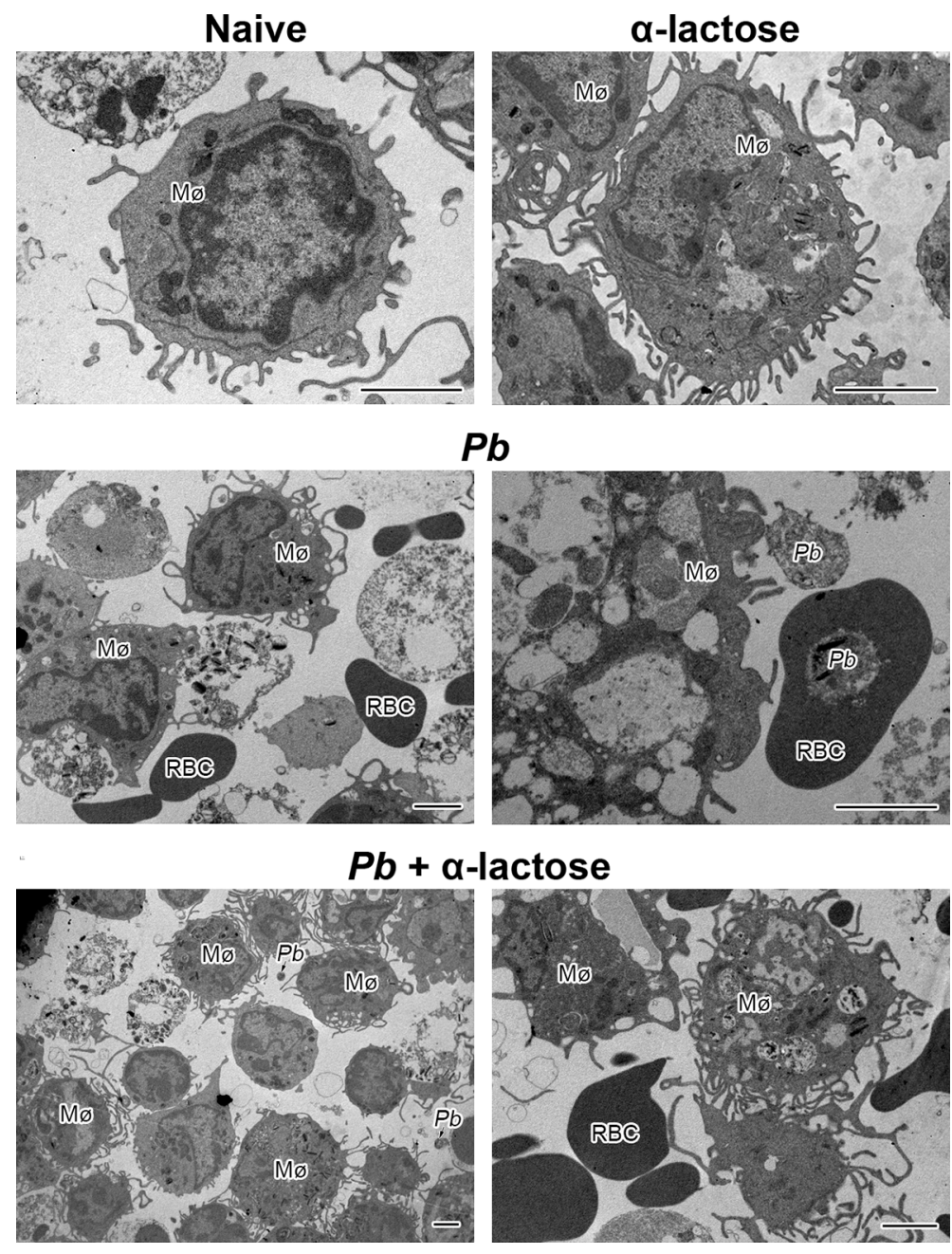

FIGURE 7 | The ultrastructures of peritoneal macrophages from PbANKA-infected mice with or without $\alpha$-lactose treatment. Mø, peritoneal macrophage; RBC, red blood cell; $P b, P$. berghei. Bar $=2 \mu \mathrm{m}$.

(35). Macrophage phagocytosis is the first line of defense of the innate immune system against malaria parasite infection (36). Hepatic histological analysis in parasitemic cases of Malawian children with fatal encephalopathy caused by $P$. falciparum revealed that increased numbers of hemozoin-laden Kupffer cells were invariably present with a strong association with histological evidence of cerebral malaria (4). Kupffer cell hyperplasia, malarial pigment within the Kupffer cells, and liver cell necrosis with portal inflammation, steatosis, and cholestasis were observed in the livers of Indian patients with fatal malaria (6). Apoptosis of Kupffer cells and portal tract lymphocytes is a significant finding in the livers of severe $P$. falciparum malaria cases (4). In this study, immunohistochemical analysis revealed that more infiltration of $\mathrm{CD} 8^{+}$macrophages were observed in the liver tissues of malarial mice treated with $\alpha$-lactose in comparison of malarial mice on days 5 and 7 p.i., indicating blockage of galectin-receptor interactions may increase the activity of macrophages during the erythrocytic stage of malaria.
Galectins, a conserved family of immunomodulatory animal lectins, are widely expressed in different tissues and a number of immune cell populations (37), and are involved in inflammation, immune responses, cell migration, autophagy, and signaling (38). So far 15 galectins have been identified in mammals (39), in which Gal-9 is expressed in a variety of tissues such as small intestine, thymus, kidney, spleen, lung, cardiac and skeletal muscles, reticulocyte, and brain, and is particularly abundant in the liver (40). It has been reported that blocking the Tim-3/ Gal-9 pathway results in the increase of IFN $\gamma$ production from hepatic effector $\mathrm{T}$ cells, which lead to exacerbated local inflammation and liver damage in a mouse model of concanavalin A-induced hepatitis, indicating the important role of Tim-3/Gal-9 signaling in the maintenance of hepatic homeostasis (41). Kupffer cells are the resident macrophage population localized within the liver sinusoid and serve as gatekeepers (42). Hepatic macrophages can arise from proliferating resident macrophages and circulating monocytes 


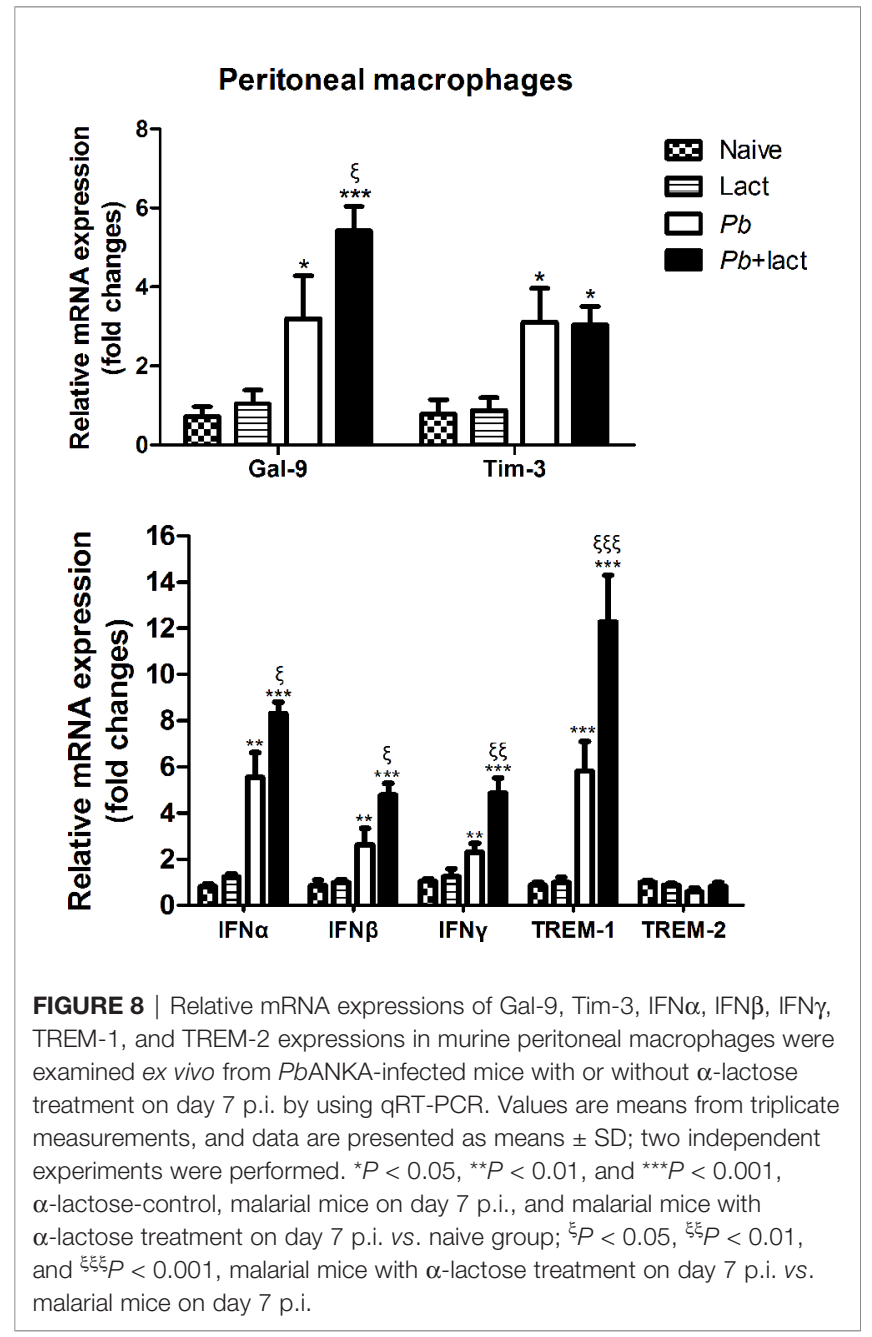

that originate from the bone marrow, which are also recruited to the injured liver $(43,44)$. Our previous study found blocking interactions of Gal-9 and its receptors (Tim-3, CD44, CD137, and protein disulfide isomerase) using $\alpha$-lactose enhances inflammatory response and exacerbates malaria-associated acute lung injury and tissue damage, indicating that Gal-9 interaction with its receptors plays a role in the development of malaria-associated acute lung injury in PbANKA-infected mouse model (26). In the present study, our data showed that by immunofluorescence assay, increased $\mathrm{CD} 68^{+}-\mathrm{Gal}-9^{+}$and CD $68^{+}$-Tim $-3^{+}$Kupffer cells/macrophages were observed in the liver tissues of malarial mice with or without $\alpha$-lactose treatment on day 7 p.i., indicating that the activity of Kupffer cells was enhanced during the erythrocytic stage of malaria, which were consistent with that of the increased mRNA levels of Gal-9 and Tim- 3 in the livers and peritoneal macrophages of malarial mice and malarial mice treated with $\alpha$-lactose. It has been reported that Gal-9 production by Kupffer cells is related to the innate and adaptive immune response (19). Our data indicate that Gal-9/ Tim-3 signaling may be involved in inflammatory immune responses to $\mathrm{PbANKA}$ infection in liver damage during the erythrocytic stage of malaria, suggesting an important mechanism for severe malaria.

Kupffer cells and infiltrating macrophages/monocytes are the major innate immune cells in the liver (45). Kupffer cells filled with damaged and parasitized erythrocytes and hemoglobin degradation pigment were observed in mice infected with $P$. chabaudi by electron microscopy (46). To further elucidate the role and regulation of galectins in activated macrophages during malaria, we investigated whether blockage of galectin-receptor interactions by $\alpha$ lactose contribute to macrophage activation during $P b A N K A$ infection. Direct ex vivo examination of macrophages revealed that the peritoneal macrophages of PbANKA-infected mice with $\alpha$-lactose treatment had more pseudopodia in comparison of those of malarial mice. In addition, the peritoneal macrophages from PbANKA-infected mice with $\alpha$ lactose treatment were able to express higher levels of Gal-9, IFN $\alpha$, IFN $\beta$, IFN $\gamma$, and TREM- 1 in comparison of those from malarial mice, suggesting that galectin-receptor interactions play a role in regulating macrophage inflammatory response during the erythrocytic stage of malaria. Our data indicate that Kupffer cells/macrophages are the predominant source of Gal9, Tim-3, IFN $\alpha$, IFN $\beta$, IFN $\gamma$, and TREM-1, and play an important role in the liver damage during the erythrocytic stage of malaria induced by $P b A N K A$ infection.

IFN-I signaling is critical for innate immune elimination of liver-stage of $P$. yoelii parasite infection (24). It has been reported that the absence of functional IFN $\alpha / \beta$ receptor pathway and IFN $\gamma$ pathway reduces murine experimental cerebral malaria-associated brain pathology induced by blood-stage PbANKA infection (47). IFN $\alpha$ and IFN $\beta$ can induce excessive inflammation (48). Activation of the IFN-I pathway may contribute to pathogenesis of cerebral malaria in Malawi (25). IFN $\gamma$ plays a critical role in mediating protective immunity against both the pre-erythrocytic and blood-stage malaria parasites (49). In the present study, our data showed significantly increased levels of IFN $\alpha$ and IFN $\gamma$ in both the livers and spleens of malarial mice treated with $\alpha$-lactose in comparison of malarial mice on day 7 p.i. It has been reported that IFN-I signaling, suppresses Th1 responses and causes experimental severe and fatal disease during $\mathrm{PbANKA}$ infection (50). IFN-I-signaling during the blood-stage of infection appears to promote $\mathrm{CD}^{+} \mathrm{T}$-cell responses in humans and mice, and may induce CTL-mediated immune-pathology (22). Anti-Gal-9 Ab treatment has been shown to significantly elevate IFN $\gamma$ production of murine splenocytes (51). Our data further demonstrated the involvement of IFN $\alpha$ and IFN $\gamma$ genes in inflammation of liver injury during the erythrocytic stage of malaria.

Apoptosis plays a principal role in normal tissue development and in the pathogenesis of different diseases (52). Gal-9 combines with Tim-3 to induce apoptosis in Th1 cells (15). Apoptosis in macrophages is responsible for immune-depression and pathological effects during malaria (29). IFN $\gamma$ limits splenic T cell numbers during $\mathrm{PbANKA}$ infection by promoting apoptosis (53). The number of apoptotic cells in the spleen were increased during acute $P$. chabaudi infection and involved both T cells, B 
A

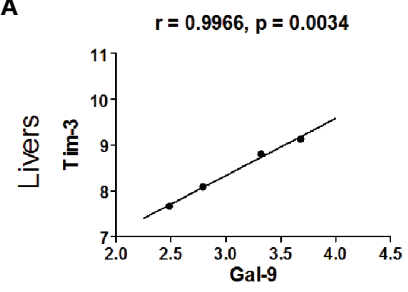

C

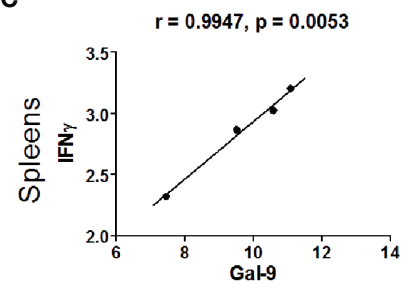

D

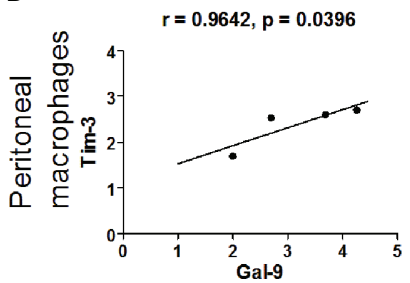

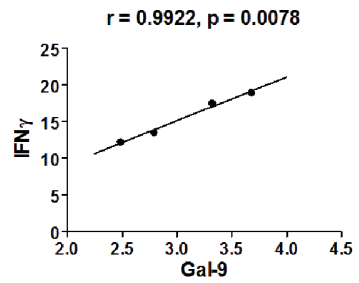
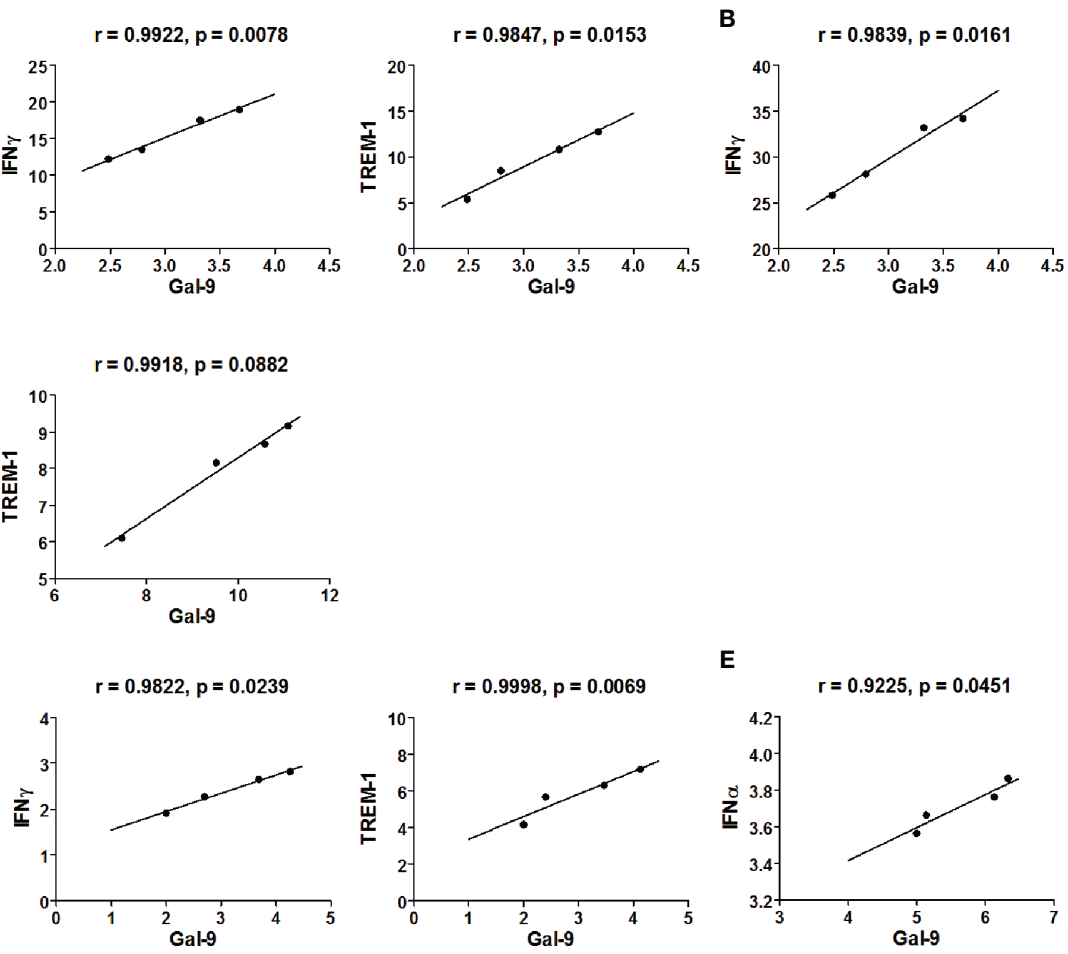

E

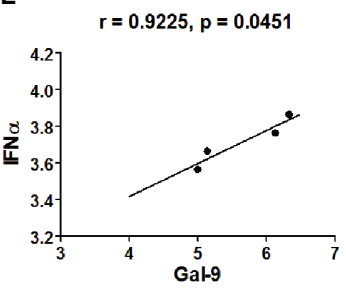

FIGURE 9 | Correlation analysis between Gal-9 and Tim-3, IFN $\alpha$, IFN $\beta$, IFN $\gamma$, or TREM-1 mRNA expression levels in the livers, spleens, and the peritoneal macrophages ex vivo from malarial mice and malarial mice with $\alpha$-lactose treatment $(n=4)$. Significant correlations between Gal-9 and Tim-3/IFN $\gamma /$ TREM-1 level in the livers of malarial mice (A) and significant correlations between Gal-9 and IFN $\gamma$ level in the livers of malarial mice with $\alpha$-lactose treatment (B). Significant correlations between Gal-9 and IFN $\gamma /$ TREM-1 level in the spleens of malarial mice (C). Significant correlations between Gal-9 and Tim-3/IFN $\gamma / T R E M-1$ level in the peritoneal macrophages isolated from malarial mice (D) and significant correlations between Gal-9 and IFN $\alpha$ level in the peritoneal macrophages isolated from malarial mice with $\alpha$-lactose treatment (E). The $r$ value generates for the theoretical line of best fit, and the $P$ value indicates the significance of the correlation.

cells, and macrophages (54). In the current study, the malarial mice with $\alpha$-lactose treatment displayed significantly higher number of TUNEL-positive cells in the livers compared with those of malarial mice, suggesting that blockage of galectinreceptor interactions may alter $\mathrm{PbANKA}$-induced inflammatory immune responses by regulating IFN-I and Type II IFN production in malarial mice.

TREM family receptors play important roles in the regulation of both innate and adaptive immune response (55), and TREM genes are expressed mainly in cells of monocyte/macrophage lineage (56). TREM-1 plays an important role in the amplification of inflammation (57). Higher soluble form of TREM-1 levels were observed among children in Ghana suffering from severe malaria compared with those of uncomplicated malaria, indicating that high plasma levels of TREM-1 were associated with the development of severe malaria (58). TREM-1 has been implicated as a biomarker of macrophage activation in human malaria patients (59). TREM-2 signaling is initially associated with negative regulation of macrophage activation (60). In this study, our data showed that the expression of TREM-1 was significantly increased in the livers, spleens, and peritoneal macrophages of malarial mice treated with $\alpha$-lactose, suggesting that the hepatic injury induced by PbANKA is caused by the local production of cytokines that activates inflammatory cells in the liver. It has been reported that the increase of plasma Gal-9 levels during falciparum malaria infection is capable of identifying severe cases and tracking the inflammation process (17). In the present study, our data indicate that Gal-9/Tim-3 pathway may regulate liver inflammation through increasing the expressions of TRRM-1, IFN $\gamma$, and IFN $\alpha$ in PbANKA-infected mice. However, the mechanism of how the IFN-I and TREM-1 influence liver injury during the erythrocytic stage of malaria required further investigation.

In conclusion, we assessed the involvement of galectins in liver inflammatory responses to murine malaria induced by PbANKA. Our data demonstrated that, blocking galectin-receptor interactions exhibited increased liver histopathology and increased activity of Kupffer cells in the livers of malarial mice due to an increase in Kupffer cell numbers, which was associated with the upregulated levels of Gal-9, Tim-3, IFN $\alpha$, IFN $\gamma$, and TREM-1 in the erythrocytic stage of malaria. Our findings reveal an important role of galectin-receptor interactions in regulating the expressions of IFN $\alpha$, IFN $\beta$, IFN $\gamma$, and TREM-1 genes during Plasmodium parasite infection and provide new insight into innate immunity to the protozoan parasites. Further studies will be necessary to elucidate how galectin-receptor interactions modulate the functions of Kupffer cells/macrophages in malariaassociated liver damage. 


\section{DATA AVAILABILITY STATEMENT}

The original contributions presented in the study are included in the article/supplementary material. Further inquiries can be directed to the corresponding authors.

\section{ETHICS STATEMENT}

The animal study was reviewed and approved by The Animal Experimentation Ethics Committee of Zhongshan School of Medicine on Laboratory Animal Care at Sun Yat-sen University (No. 2016-081).

\section{AUTHOR CONTRIBUTIONS}

FL designed the experiments, analyzed data, wrote, and edited the manuscript. SH revised and edited the manuscript. YW, SX,

\section{REFERENCES}

1. White NJ. The Treatment of Malaria. N Engl J Med (1996) 335(11):800-6. doi: 10.1056/NEJM199609123351107

2. Wilairatana P, Looareesuwan S, Charoenlarp P. Liver Profile Changes and Complications in Jaundiced Patients With Falciparum Malaria. Trop Med Parasitol (1994) 45(4):298-302.

3. Kochar DK, Agarwal P, Kochar SK, Jain R, Rawat N, Pokharna RK, et al. Hepatocyte Dysfunction and Hepatic Encephalopathy in Plasmodium Falciparum Malaria. QJM (2003) 96(7):505-12. doi: 10.1093/qjmed/hcg091

4. Viriyavejakul P, Khachonsaksumet V, Punsawad C. Liver Changes in Severe Plasmodium Falciparum Malaria: Histopathology, Apoptosis and Nuclear Factor Kappa B Expression. Malar J (2014) 13:106. doi: 10.1186/1475-287513-106

5. Gonçalves LA, Rodo J, Rodrigues-Duarte L, de Moraes LV, Penha-Gonçalves C. HGF Secreted by Activated Kupffer Cells Induces Apoptosis of PlasmodiumInfected Hepatocytes. Front Immunol (2017) 8:90. doi: 10.3389/ fimmu.2017.00090

6. Rupani AB, Amarapurkar AD. Hepatic Changes in Fatal Malaria: An Emerging Problem. Ann Trop Med Parasitol (2009) 103(2):119-27. doi: 10.1179/ 136485909X385054

7. Whitten R, Milner DAJr, Yeh MM, Kamiza S, Molyneux ME, Taylor TE. Liver Pathology in Malawian Children With Fatal Encephalopathy. Hum Pathol (2011) 42(9):1230-9. doi: 10.1016/j.humpath.2010.11.019

8. Klesney-Tait J, Turnbull IR, Colonna M. The TREM Receptor Family and Signal Integration. Nat Immunol (2006) 7(12):1266-73. doi: 10.1038/ni1411

9. Turnbull IR, Gilfillan S, Cella M, Aoshi T, Miller M, Piccio L, et al. Cutting Edge: TREM-2 Attenuates Macrophage Activation. J Immunol (2006) 177 (6):3520-4. doi: 10.4049/jimmunol.177.6.3520

10. Watarai H, Sekine E, Inoue S, Nakagawa R, Kaisho T, Taniguchi M. PDCTREM, a Plasmacytoid Dendritic Cell-Specific Receptor, Is Responsible for Augmented Production of Type I Interferon. Proc Natl Acad Sci USA (2008) 105(8):2993-8. doi: 10.1073/pnas.0710351105

11. Nguyen-Lefebvre AT, Ajith A, Portik-Dobos V, Horuzsko DD, Arbab AS, Dzutsev A, et al. The Innate Immune Receptor TREM-1 Promotes Liver Injury and Fibrosis. J Clin Invest (2018) 128(11):4870-83. doi: 10.1172/JCI98156

12. Gonçalves LA, Rodrigues-Duarte L, Rodo J, Vieira de Moraes L, Marques I, Penha-Gonçalves C. TREM2 Governs Kupffer Cell Activation and Explains Belr1 Genetic Resistance to Malaria Liver Stage Infection. Proc Natl Acad Sci USA (2013) 110(48):19531-6. doi: 10.1073/pnas.1306873110

13. Rabinovich GA, Toscano MA. Turning 'Sweet' on Immunity: Galectin-Glycan Interactions in Immune Tolerance and Inflammation. Nat Rev Immunol (2009) 9(5):338-52. doi: 10.1038/nri2536 and $\mathrm{JH}$ conducted experiments and analyzed data. All authors contributed to the article and approved the submitted version.

\section{FUNDING}

This work was supported by the National Natural Science Foundation of China (81971955); the Natural Science Foundation of Guangdong Province (2019A1515011667, 2021A1515012115); 2021 Graduate Education Innovation Plan Project of Guangdong Province (2021SFKC003); Guangdong Basic and Applied Basic Research Foundation (2019A1515011318); Shenzhen Science and Technology Innovation Commission Basic Research Foundation (JCYJ20180307150637015); the Undergraduate Teaching Quality Engineering Project of Sun Yat-sen University (SYSU Undergraduate Education [2021]93, SYSU Undergraduate Education [2020]72); the Open Project of Key Laboratory of Tropical Disease Control of Ministry of Education, Sun Yat-sen University (2020ZX02).

14. Baum LG, Garner OB, Schaefer K, Lee B. Microbe-Host Interactions Are Positively and Negatively Regulated by Galectin-Glycan Interactions. Front Immunol (2014) 5:284. doi: 10.3389/fimmu.2014.00284

15. Zhu C, Anderson AC, Schubart A, Xiong H, Imitola J, Khoury SI, et al. The Tim-3 Ligand Galectin-9 Negatively Regulates T Helper Type 1 Immunity. Nat Immunol (2005) 6(12):1245-52. doi: 10.1038/ni1271

16. Golden-Mason L, Rosen HR. Galectin-9: Diverse Roles in Hepatic Immune Homeostasis and Inflammation. Hepatology (2017) 66(1):271-9. doi: 10.1002/ hep. 29106

17. Dembele BP, Chagan-Yasutan H, Niki T, Ashino Y, Tangpukdee N, Shinichi E, et al. Plasma Levels of Galectin-9 Reflect Disease Severity in Malaria Infection. Malar J (2016) 15(1):403. doi: 10.1186/s12936-016-1471-7

18. Xiao S, Liu J, Huang S, Lu F. Increased Gal-9 and Tim-3 Expressions During Liver Damage in a Murine Malarial Model. Parasitol Res (2016) 115(2):66372. doi: 10.1007/s00436-015-4784-5

19. Mengshol JA, Golden-Mason L, Arikawa T, Smith M, Niki T, McWilliams R, et al. A Crucial Role for Kupffer Cell-Derived Galectin-9 in Regulation of T Cell Immunity in Hepatitis C Infection. PloS One (2010) 5(3):e9504 doi: 10.1371/journal.pone.0009504

20. McNab F, Mayer-Barber K, Sher A, Wack A, O'Garra A. Type I Interferons in Infectious Disease. Nat Rev Immunol (2015) 15(2):87-103. doi: 10.1038/ nri378

21. Ball EA, Sambo MR, Martins M, Trovoada MJ, Benchimol C, Costa J, et al. IFNAR1 Controls Progression to Cerebral Malaria in Children and CD8 ${ }^{+} \mathrm{T}$ Cell Brain Pathology in Plasmodium Berghei-Infected Mice. J Immunol (2013) 190(10):5118-27. doi: 10.4049/jimmunol.1300114

22. Sebina I, Haque A. Effects of Type I Interferons in Malaria. Immunology (2018) 155(2):176-85. doi: 10.1111/imm.129717

23. Liehl P, Zuzarte-Luís V, Chan J, Zillinger T, Baptista F, Carapau D. Host-Cell Sensors for Plasmodium Activate Innate Immunity Against Liver-Stage Infection. Nat Med (2014) 20(1):47-53. doi: 10.1038/nm.3424

24. Miller JL, Sack BK, Baldwin M, Vaughan AM, Kappe SHI. InterferonMediated Innate Immune Responses Against Malaria Parasite Liver Stages. Cell Rep (2014) 7(2):436-47. doi: 10.1016/j.celrep.2014.03.018

25. Feintuch CM, Tare A, Cusumano LR, Benayoun J, Ryu S, Sixpence A, et al Type I Interferon Receptor Variants in Gene Regulatory Regions are Associated With Susceptibility to Cerebral Malaria in Malawi. Am J Trop Med Hyg (2018) 98(6):1692-8. doi: 10.4269/ajtmh.17-0887

26. Liu J, Huang S, Su XZ, Song J, Lu F. Blockage of Galectin-Receptor Interactions by $\alpha$ Lactose Exacerbates Plasmodium Berghei-Induced Pulmonary Immunopathology. Sci Rep (2016) 6:32024. doi: 10.1038/srep32024

27. Sehrawat S, Reddy PB, Rajasagi N, Suryawanshi A, Hirashima M, Rouse BT. Galectin-9/TIM-3 Interaction Regulates Virus-Specific Primary and Memory 
CD8 T Cell Response. PloS Pathog (2010) 6(5):e1000882. doi: 10.1371/ journal.ppat.1000882

28. Fazalul Rahiman SS, Basir R, Talib H, Tie TH, Chuah YK, Jabbarzare M, et al. Interleukin-27 Exhibited Anti-Inflammatory Activity During Plasmodium Berghei Infection in Mice. Trop BioMed (2013) 30(4):663-80.

29. Deshmukh R, Trivedi V. Phagocytic Uptake of Oxidized Heme Polymer is Highly Cytotoxic to Macrophages. PloS One (2014) 9(7):e103706. doi: 10.1371/ journal.pone.0103706

30. Murthi P, Kalionis B, Ghabrial H, Dunlop ME, Smallwood RA, Sewell RB. Kupffer Cell Function During the Erythocytic Stage of Malaria. J Gastroenterol Hepatol (2006) 21(1 Pt 2):313-8. doi: 10.1111/j.1440-1746.2006.04192.x

31. Nobes MS, Ghabrial H, Simms KM, Smallwood RB, Morgan DJ, Sewell RB. Hepatic Kupffer Cell Phagocytotic Function in Rats With Erythrocytic-Stage Malaria. J Gastroenterol Hepatol (2002) 17(5):598-605. doi: 10.1046/j.14401746.2002.02742.x

32. Grau GE, Heremans H, Piguet PF, Pointaire P, Lambert PH, Billiau A, et al. Monoclonal Antibody Against Interferon Gamma can Prevent Experimental Cerebral Malaria and its Associated Overproduction of Tumor Necrosis Factor. Proc Natl Acad Sci USA (1989) 86 14:5572-4. doi: 10.1073/pnas.86.14.5572

33. Chin VK, Asyran AMY, Zakaria ZA, Abdullah WO, Chong PP, Nordin N, et al. TREM-1 Modulation Produces Positive Outcome on the Histopathology and Cytokines Release Profile of Plasmodium Berghei-Infected Mice. J Parasit Dis (2019) 43(1):139-53. doi: 10.1007/s12639-018-1070-3

34. Frevert U, Nardin E. Cellular Effector Mechanisms Against Plasmodium Liver Stages. Cell Microbiol (2008) 10(10):1956-67. doi: 10.1111/j.1462-5822.2008. 01211.x

35. Krücken J, Delić D, Pauen H, Wojtalla A, El-Khadragy M, Dkhil, et al. Augmented Particle Trapping and Attenuated Inflammation in the Liver by Protective Vaccination Against Plasmodium Chabaudi Malaria. Malar J (2009) 8:54. doi: 10.1186/1475-2875-8-54

36. Mohamad D, Suppian R, Mohd Nor N. Immunomodulatory Effects of Recombinant BCG Expressing MSP-1C of Plasmodium falciparum on LPSor LPS+IFN- $\gamma$-Stimulated J774A.1 Cells. Hum Vaccin Immunother (2014) 10 (7):1880-6. doi: 10.4161/hv.28695

37. Vasta GR. Galectins as Pattern Recognition Receptors: Structure, Function, and Evolution. Adv Exp Med Biol (2012) 946:21-36. doi: 10.1007/978-1-46140106-3_2

38. Johannes L, Jacob R, Leffler H. Galectins at a Glance. J Cell Sci (2018) 131(9): jcs208884. doi: 10.1242/jcs.208884

39. van Kooyk Y, Rabinovich GA. Protein-Glycan Interactions in the Control of Innate and Adaptive Immune Responses. Nat Immunol (2008) 9(6):593-601. doi: 10.1038/ni.f.203

40. Wada J, Kanwar YS. Identification and Characterization of Galectin-9, a Novel Beta-Galactoside-Binding Mammalian Lectin. J Biol Chem (1997) 272 (9):6078-86. doi: 10.1074/jbc.272.9.6078

41. Ju Y, Shang X, Liu Z, Zhang J, Li Y, Shen Y, et al. The Tim-3/Galectin-9 Pathway Involves in the Homeostasis of Hepatic Tregs in a Mouse Model of Concanavalin A-Induced Hepatitis. Mol Immunol (2014) 58(1):85-91. doi: 10.1016/j.molimm.2013.11.001

42. Meijer C, Wiezer MJ, Diehl AM, Schouten HJ, Schouten HJ, Meijer S, et al. Kupffer Cell Depletion by CI2MDP-Liposomes Alters Hepatic Cytokine Expression and Delays Liver Regeneration After Partial Hepatectomy. Liver (2000) 20(1):66-77. doi: 10.1034/j.1600-0676.2000.020001066.x

43. Duffield JS, Forbes SJ, Constandinou CM, Clay S, Partolina M, Vuthoori S, et al. Selective Depletion of Macrophages Reveals Distinct, Opposing Roles During Liver Injury and Repair. J Clin Invest (2005) 115(1):56-65. doi: 10.1172/ JCI2005226756

44. Wynn TA, Vannella KM. Macrophages in Tissue Repair, Regeneration, and Fibrosis. Immunity (2016) 44(3):450-62. doi: 10.1016/j.immuni.2016.02.015

45. Boltjes A, Movita D, Boonstra A, Woltman AM. The Role of Kupffer Cells in Hepatitis B and Hepatitis C Virus Infections. J Hepatol (2014) 61(3):660-71. doi: 10.1016/j.jhep.2014.04.026

46. Bellows CF, Molina RM, Brain JD. Diminished Organelle Motion in Murine Kupffer Cells During the Erythrocytic Stage of Malaria. J R Soc Interface (2011) 8(58):711-9. doi: 10.1098/rsif.2010.0260

47. Palomo J, Fauconnier M, Coquard L, Gilles M, Meme S, Szeremeta F, et al. Type I Interferons Contribute to Experimental Cerebral Malaria Development in Response to Sporozoite or Blood-Stage Plasmodium Berghei ANKA. Eur J Immunol (2013) 43(10):2683-95. doi: 10.1002/eji.201343327

48. Trinchieri G. Type I Interferon: Friend or Foe? J Exp Med (2010) 207 (10):2053-63. doi: 10.1084/jem.20101664

49. McCall MB, Sauerwein RW. Interferon- $\gamma$-Central Mediator of Protective Immune Responses Against the Pre-Erythrocytic and Blood Stage of Malaria. J Leukoc Biol (2010) 88(6):1131-43. doi: 10.1189/jlb.0310137

50. Haque A, Best SE, Montes de Oca M, James KR, Ammerdorffer A, Edwards CL, et al. Type I IFN Signaling in CD8-DCs Impairs Th1-Dependent Malaria Immunity. J Clin Invest (2014) 124(6):2483-96. doi: 10.1172/ JCI70698

51. Fukushima A, Sumi T, Fukuda K, Kumagai N, Nishida T, Okumura K, et al. Roles of Galectin-9 in the Development of Experimental Allergic Conjunctivitis in Mice. Int Arch Allergy Immunol (2008) 146(1):36-43. doi: $10.1159 / 000112501$

52. DosReis GA, Barcinski MA. Apoptosis and Parasitism: From the Parasite to the Host Immune Response. Adv Parasi (2001) 49:133-61. doi: 10.1016/s0065$308 \mathrm{x}(01) 49039-7$

53. Villegas-Mendez A, de Souza JB, Murungi L, Hafalla JC, Shaw TN, Greig R, et al. Heterogeneous and Tissue-Specific Regulation of Effector $\mathrm{T}$ Cell Responses by IFN-Gamma During Plasmodium Berghei ANKA Infection. J Immunol (2011) 187(6):2885-97. doi: 10.4049/jimmunol.1100241

54. Helmby H, Jönsson G, Troye-Blomberg M. Cellular Changes and Apoptosis in the Spleens and Peripheral Blood of Mice Infected With Blood-Stage Plasmodium Chabaudi Chabaudi AS. Infect Immun (2000) 68(3):1485-90. doi: 10.1128/IAI.68.3.1485-1490.2000

55. Won KJ, Park SW, Lee S, Kong IK, Chae JI, Kim B, et al. A New Triggering Receptor Expressed on Myeloid Cells (TREM) Family Member, TLT-6, is Involved in Activation and Proliferation of Macrophages. Immune Netw (2015) 15(5):232-40. doi: 10.4110/in.2015.15.5.232

56. Ford JW, McVicar DW. TREM and TREM-Like Receptors in Inflammation and Disease. Curr Opin Immunol (2009) 21(1):38-46. doi: 10.1016/ j.coi.2009.01.009

57. Yuan Z, Syed MA, Panchal D, Joo M, Colonna M, Brantly M, et al. Triggering Receptor Expressed on Myeloid Cells 1 (TREM-1)-Mediated Bcl-2 Induction Prolongs Macrophage Survival. J Biol Chem (2014) 289(21):15118-29. doi: 10.1074/jbc.M113.536490

58. Adukpo S, Gyan BA, Ofori MF, Dodoo D, Velavan TP, Meyer CG. Triggering Receptor Expressed on Myeloid Cells 1 (TREM-1) and Cytokine Gene Variants in Complicated and Uncomplicated Malaria. Trop Med Int Health (2016) 21(12):1592-601. doi: 10.1111/tmi.12787

59. Chimma P, Roussilhon C, Sratongno P, Ruangveerayuth R, Pattanapanyasat K, Pérignon JL, et al. A Distinct Peripheral Blood Monocyte Phenotype Is Associated With Parasite Inhibitory Activity in Acute Uncomplicated Plasmodium falciparum Malaria. PloS Pathog (2009) 5(10):e1000631. doi: 10.1371/journal.ppat.1000631

60. Sharif O, Knapp S. From Expression to Signaling: Roles of TREM-1 and TREM-2 in Innate Immunity and Bacterial Infection. Immunobiology (2008) 213(9-10):701-13. doi: 10.1016/j.imbio.2008.07.008

Conflict of Interest: The authors declare that the research was conducted in the absence of any commercial or financial relationships that could be construed as a potential conflict of interest.

Publisher's Note: All claims expressed in this article are solely those of the authors and do not necessarily represent those of their affiliated organizations, or those of the publisher, the editors and the reviewers. Any product that may be evaluated in this article, or claim that may be made by its manufacturer, is not guaranteed or endorsed by the publisher.

Copyright (c) $2021 \mathrm{Wu}$, Huang, Xiao, He and Lu. This is an open-access article distributed under the terms of the Creative Commons Attribution License (CC BY). The use, distribution or reproduction in other forums is permitted, provided the original author(s) and the copyright owner(s) are credited and that the original publication in this journal is cited, in accordance with accepted academic practice. No use, distribution or reproduction is permitted which does not comply with these terms. 